\title{
Residual stress in expanded austenite on stainless steel; origin, measurement, and
} prediction

Somers, Marcel A.J.; Kücükyildiz, Ömer C.; Ormstrup, Casper A.; Alimadadi, Hossein; Hattel, Jesper H.; Christiansen, Thomas L.; Winther, Grethe

Published in:

Materials Performance and Characterization

Link to article, DOI:

10.1520/MPC20170145

Publication date:

2018

Document Version

Publisher's PDF, also known as Version of record

Link back to DTU Orbit

Citation $(A P A)$ :

Somers, M. A. J., Kücükyildiz, Ö. C., Ormstrup, C. A., Alimadadi, H., Hattel, J. H., Christiansen, T. L., \& Winther, G. (2018). Residual stress in expanded austenite on stainless steel; origin, measurement, and prediction. Materials Performance and Characterization, 7(4), 693-716. https://doi.org/10.1520/MPC20170145

\section{General rights}

Copyright and moral rights for the publications made accessible in the public portal are retained by the authors and/or other copyright owners and it is a condition of accessing publications that users recognise and abide by the legal requirements associated with these rights.

- Users may download and print one copy of any publication from the public portal for the purpose of private study or research.

- You may not further distribute the material or use it for any profit-making activity or commercial gain

- You may freely distribute the URL identifying the publication in the public portal 


\section{REVIEW PAPER}

Manuscript received September 25, 2017; accepted for publication December 21, 2017; published online June 19, 2018.

1 Department of Mechanical Engineering, Technical University of Denmark, Produktionstorvet, B. 425, 2800 Kongens Lyngby, Denmark (Corresponding author), e-mail: somers@mek.dtu.dk. (i) https://orcid.org/0000-00017773-1432

2 Department of Mechanical Engineering, Technical University of Denmark, Produktionstorvet, B. 425, 2800 Kongens Lyngby, Denmark

3 Center for Electron Nanoscopy, Technical University of Denmark, Fysikvej, B. 307, 2800 Kongens Lyngby, Denmark
Marcel A. J. Somers, ${ }^{1}$ Ömer C. Kücükyildiz, ${ }^{2}$ Casper A. Ormstrup, ${ }^{2}$ Hossein Alimadadi, ${ }^{3}$ Jesper H. Hattel, ${ }^{2}$ Thomas L. Christiansen, ${ }^{2}$ and Grethe Winther ${ }^{2}$

\section{Residual Stress in Expanded Austenite on Stainless Steel; Origin, Measurement, and Prediction}

\section{Reference}

Somers, M. A. J., Kücükyildiz, Ömer C., Ormstrup, C. A., Alimadadi, H., Hattel, J. H., Christiansen, T. L., and Winther, G., "Residual Stress in Expanded Austenite on Stainless Steel; Origin, Measurement, and Prediction," Materials Performance and Characterization, Vol. 7, No. 4, 2018, pp. 693-716, https://doi.org/10.1520/MPC20170145. ISSN 2379-1365

\section{ABSTRACT}

Expanded austenite is a supersaturated solid solution of nitrogen/carbon in austenite that forms as a case by the diffusion of nitrogen/carbon into austenitic stainless steel. Expanded austenite has a high level of hardness that provides resistance against galling and wear, superior resistance against localized corrosion, and contributes to improvement of the fatigue performance. This latter characteristic is a consequence of the huge compressive residual stresses in the expanded austenite case. Such stresses are induced by the high interstitial content in the austenite lattice and are accommodated elasto-plastically. The experimental assessment of the elastic lattice strains is complicated by the presence of steep composition-depth and stress-depth profiles, which necessitate special measurement or correction procedures to unravel the influence of composition and stress on the lattice spacing and avoid artifacts arising from (steep) lattice-spacing gradients. In the present work the $\sin ^{2} \psi$ method was combined with grazing incidence $X$-ray diffraction to keep the information depth during measurement shallow, independent of the (effective) tilt angle $\psi$. The plastic strains in the expanded austenite 27 zone were estimated from the lattice rotations, as determined with electron backscatter diffraction. It is demonstrated that the level of elastic lattice strains in expanded austenite can be adjusted by retracting part of the dissolved nitrogen. The experimental results for elastic and plastic strains are compared to those predicted by a comprehensive numerical 
model that simulates the time-dependent development of composition-depth and stress-depth profiles in expanded austenite. The work described in this manuscript is a combination of a review of previously achieved and published results as well as the newest results of ongoing research activities.

\section{Keywords}

expanded austenite, residual stress measurement, X-ray diffraction, stress modeling

\section{Introduction}

Since the mid-eighties of the previous century, surface hardening of primarily austenitic stainless steel by the dissolution of nitrogen, carbon atoms, or both has developed into a commercially successful remedy against galling and wear and has further improved the corrosion performance, in particular with respect to localized corrosion, i.e., pitting and crevice corrosion. For a description of the historical development, the process variants, and the obtainable properties and performance improvement, the reader is referred to recent comprehensive reviews of the topic [1-5]. The microstructure developing during low temperature surface hardening of stainless steel consists of a zone of a supersaturated solid solution of interstitial atoms (N, C, or both) in austenite, called expanded austenite. ${ }^{4}$ Expanded austenite refers to an expansion of the crystal lattice as a consequence of the (colossal) interstitial content in supersaturated solid solution, which, expressed as the number of interstitials per metal atom, amounts to up to 0.61 or 0.22 for nitrogen and carbon, respectively [6,7]. As a consequence of the lattice expansion, which with the highest nitrogen content reaches $11 \%$ for the lattice parameter, huge compressive residual stresses develop. The experimental determination of these residual stresses with diffraction techniques in the hard case of expanded austenite is not a trivial task, because (steep) gradients in the stress and composition can arise. In particular the composition profile can lead to anomalies in the stress values determined by routine analysis, as in, for example, the $\sin ^{2} \psi$ method [8].

This article addresses the origin, measurement, and prediction of such residual stresses.

\section{Origin of Residual Stress in Expanded Austenite}

From a thermodynamic point of view, the interstitial solubility of the nitrogen and carbon in austenitic stainless steel is very low and will readily lead to the development of nitrides or carbides. The nitride/carbide forming constituent of concern is chromium, which is the main alloying element in stainless steels that provides protection against corrosion. Removing chromium from solid solution by nitride/carbide formation jeopardizes the inherent corrosion protection, as chromium is no longer abundantly present to develop a passivating oxide layer at the surface. Only for relatively high temperatures, say 1,250 K, is nitrogen dissolved in austenite to a certain extent, without nitride formation (see an example for the isopleth and isobars of the dissolution of N in AISI 316 in Fig. 1a [9]). For a high nitrogen content, a high solution nitriding temperature and a high $\mathrm{N}_{2}$ pressure are necessary. For carbon, the solubility at high temperature is lower than for nitrogen, and the

${ }^{4}$ The developing case is also referred to as S-phase, but this is not preferred in the present work, because the case is not a new phase as suggested by the name S-phase. This is merely a remnant of early work on the topic, when the identity of the developing case was insufficiently understood (see Ref. [4]). 
FIG. 1

\section{(a) Isopleth for AISI 316 with} various nitrogen contents, calculated with ThermoCalc using database TCFE7

(ThermoCalc Software, Stockholm, Sweden). The gray lines are isobars for the $\mathrm{N}_{2}$ pressure [9]. (b) Schematic TTT diagram for nitrogen/carbon containing austenite, showing the time available before chromium nitrides/carbides develop. High-temperature solution nitriding can be performed for temperatures where austenite is stable, and the equilibrium content follows from the combination of temperature and isobar in (a).

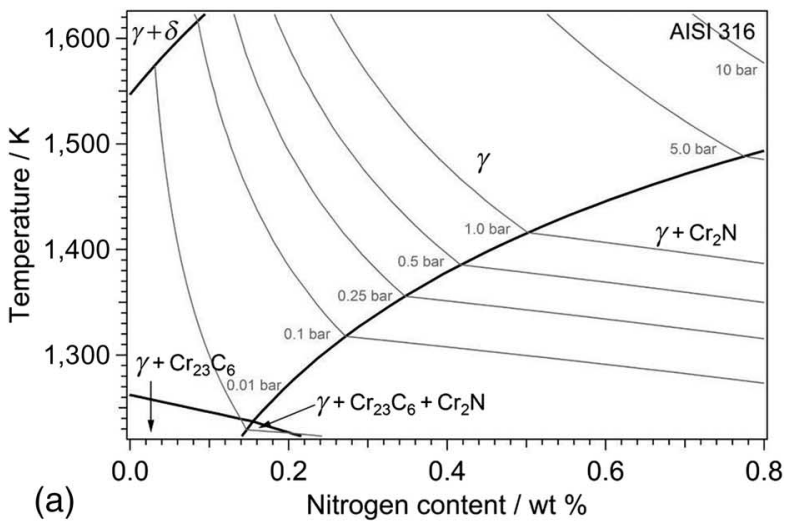

High temperature solution nitriding

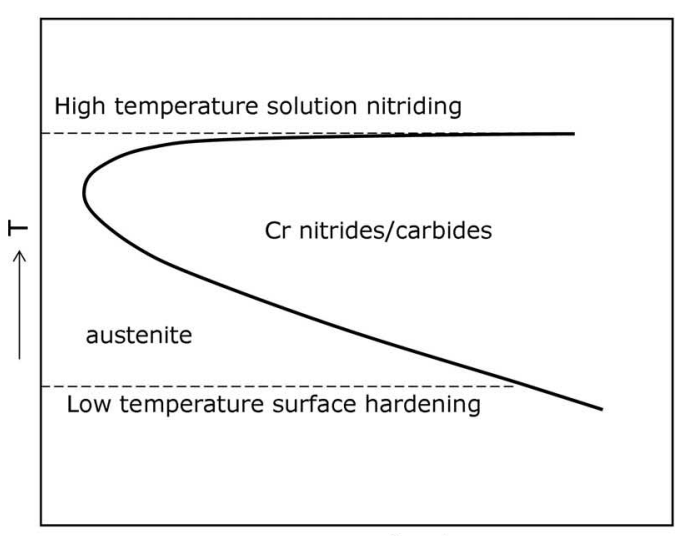

(b) $\rightarrow \log t$

composition and temperature range is narrow. Furthermore, for solution carburizing of stainless steel, the cooling is even more critical than for solution nitriding. For these reasons solution carburizing is not practically feasible.

From a kinetics point of view, the development of chromium nitrides/carbides can be delayed by dissolving nitrogen/carbon at a relatively low temperature. This is schematically illustrated in Fig. 1b, in a time-temperature-transformation (TTT) diagram, and referred to as "low temperature surface hardening." At relatively low temperatures the interstitials are mobile while they diffuse over the octahedral interstices of the austenite lattice, while the substitutional dissolved atoms as chromium diffuse very slowly. Consequently, in the competition between interstitial diffusion and nitride/carbide formation, a certain depth can be reached by the interstitial atoms before the first nucleation of chromium-based nitrides/carbides. Consider in this respect that in chromium nitride $(\mathrm{CrN})$ the $\mathrm{Cr}: \mathrm{N}$ ratio is $1: 1$, and each chromium ( $\mathrm{Cr}$ ) atom in the sodium chloride-type cubic lattice is surrounded by 6 nitrogen $(\mathrm{N})$ atoms (but shared with other $\mathrm{Cr}$ atoms). On the other hand, in a solid solution in face centered cubic (f.c.c.), $\mathrm{Cr}$ tries to obtain as many $\mathrm{N}$ neighbors as possible. Experimentally $\mathrm{Cr}: \mathrm{N}$ ratios in excess of 1:3 have been observed [8], where on average each $\mathrm{Cr}$ atom has $5 \mathrm{~N}$ neighbors [10]. Also, since there is a strong affinity between chromium and, in particular, nitrogen atoms, a high metastable solubility of nitrogen (and to a lesser extent of carbon) can be reached, which by far exceeds the nitrogen that can be 
FIG. 2

Dependence of the strain-free lattice parameter of homogeneous expanded austenite foils of uniform composition on the interstitial content of interstitials in solid solution (data from Refs. [8,12] and reinterpreted in Ref. [13]).

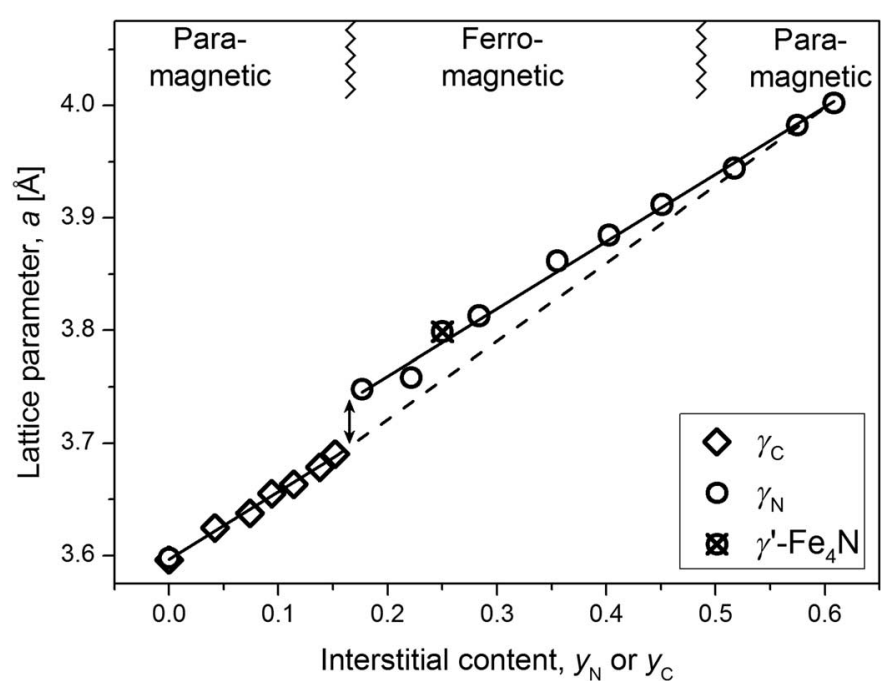

bound in $\mathrm{CrN}$ and dissolved in the austenite matrix. This implies that a (strongly) supersaturated solid solution, also referred to as colossal supersaturation $[8,11]$, is obtained.

The effect of the dissolution of carbon and nitrogen atoms in austenite at low temperatures on the lattice parameter of austenite has been experimentally determined for stressfree homogeneous powders and foils $[8,12]$ and shows an expansion of up to $11 \%$ in the lattice parameter. See in this respect Fig. 2 [13], where the stress-free lattice parameter is given as a function of the occupancy of octahedral interstices, $\mathrm{y}_{\mathrm{N}}$ or $\mathrm{y}_{\mathrm{C}}$, which for an f.c.c. lattice equals the number of interstitials per metal atom.

The discontinuity at $y_{N}=0.17$ is a consequence of a magnetic transition in austenite [13]. In practice expanded austenite is not used as a thin foil of uniform composition, but rather as a case reaching to a certain depth into austenitic stainless steel with a concentration-depth profile. Fig. 3a shows a nitrogen concentration depth-profile as determined by Glow Discharge Optical Emission Spectroscopy (GD-OES), while the shift of 111- and 200-line profiles to lower Bragg angles is shown for different depths in Fig. 3b [14].

As a consequence of the lattice expansion associated with nitrogen/carbon dissolution, the concentration profile leads to a profile in lattice expansion, which is accommodated by residual compressive stress and compensated with tensile stresses deeper in the steel. The colossal dissolution of interstitials into austenite leads to solid solution strengthening, implying an increase of the yield stress and the hardness. It is this increase in hardness that is the objective of the treatment, to enhance the wear (and galling) resistance without impairing the corrosion resistance (hence the prevention of nitrides/carbides). It has been demonstrated that elastic accommodation of the lattice expansion leads to unrealistically high compressive stresses that by far outweigh the yield strength of the solution-strengthened stainless steel [15]. Consequently, plastic accommodation of the lattice expansion also occurs, which is manifested as lattice rotation, surface roughening, and eventually grain push-out and brittle fracture $[6,16,17]$.

As compared to virtually interstitial-free austenite, the higher the content of interstitials in paramagnetic expanded austenite, the lower the thermal expansion coefficient (see Fig. 4 [13,18]). Moreover, below the Curie temperature, the thermal expansion 
FIG. 3

\section{(a) Nitrogen profile obtained} with GD-OES, and (b) X-ray diffractograms of the AISI $316 \mathrm{~L}$ steel gas nitrided at $703 \mathrm{~K}$ for $20 \mathrm{~h}$, obtained by symmetric $\mathrm{X}$-ray diffraction. From top to bottom: as-nitrided surface and after removing $6 \mu \mathrm{m}, 11 \mu \mathrm{m}$, and $17 \mu \mathrm{m}$. The latter corresponds to untreated bulk austenite. The arrows in the GD-OES profile show the (approximate) positions of the surface positions for the diffractograms in (b) [14].
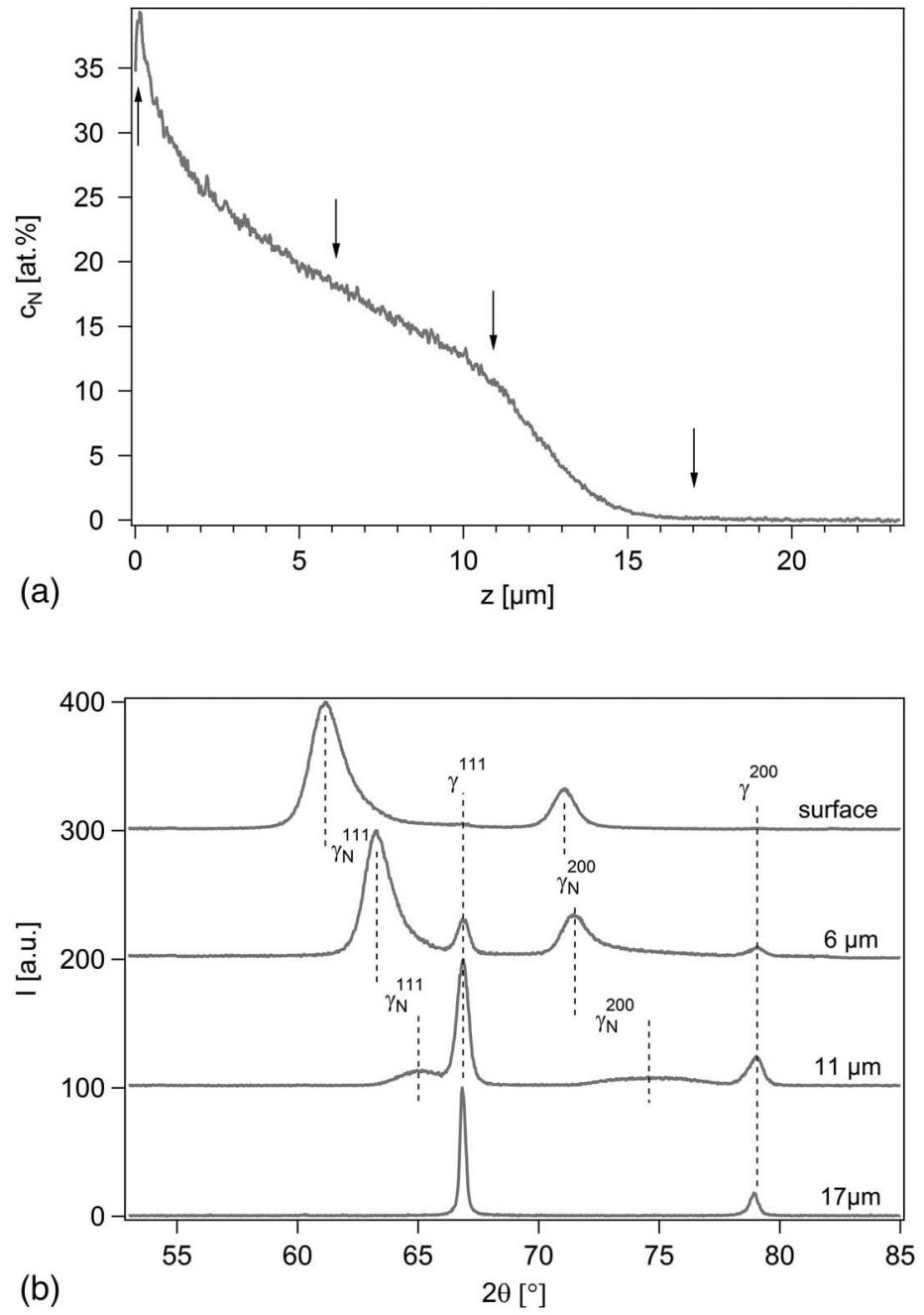
FIG. 4

Coefficients of linear thermal expansion versus strain-free lattice parameter at room temperature for expanded austenite, including the value for strictly ordered iron nitride [36]. The dashed lines are drawn to guide the eye [18].

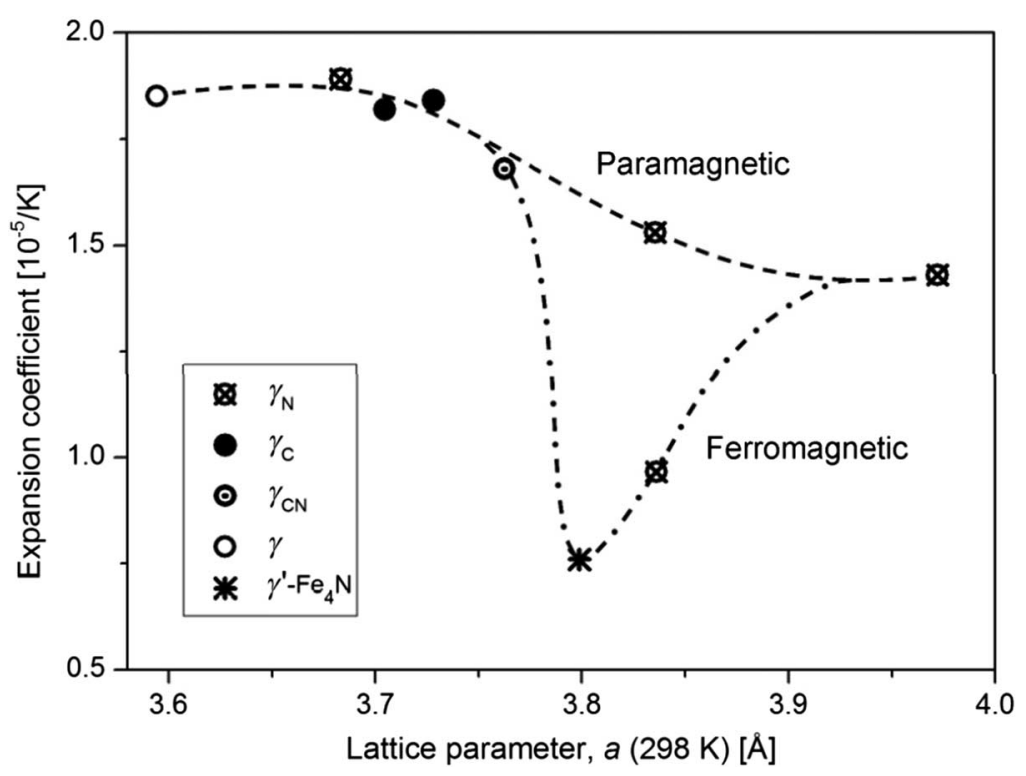

lattice strain, $\varepsilon_{\psi}^{h k l}$, experienced in a family of lattice planes $\{h k l\}$ in a direction defined by the (effective) tilt angle, $\psi$, with respect to the surface normal, can be expressed as:

$$
\varepsilon_{\psi}^{h k l}=\frac{d_{\psi}^{h k l}-d_{\varepsilon=0}^{h k l}}{d_{\varepsilon=0}^{h k l}}=\frac{1}{2} S_{2}^{h k l} \sigma_{/ /} \sin ^{2} \psi+2 S_{1}^{h k l} \sigma_{/ /}
$$

where $d_{\psi}^{h k l}$ is the associated lattice spacing, $d_{\varepsilon=0}^{h k l}$ is the strain-free lattice spacing, and $S_{1}^{h k l}$ and $\frac{1}{2} S_{2}^{h k l}$ are X-ray elastic constants (XECs), depending on the material and on the $\{h k l\}$. From equating Eq 1 to zero and rearranging terms, it follows that $d_{\varepsilon=0}^{h k l}$ in Eq 1 is experienced in what is called the strain-free measurement direction, $\psi_{\varepsilon=0}$, defined as:

$$
\sin ^{2} \psi_{\varepsilon=0}=\frac{-2 S_{1}^{h k l}}{\frac{1}{2} S_{2}^{h k l}}
$$

Hence, from the measurement of $d_{\psi}^{h k l}$ for various values of $\sin ^{2} \psi$ and repeating this at various depths, it should be possible to retrieve the stress-depth profile and the strain-free lattice parameter profile. The latter can be translated to the composition-depth profile over the expanded austenite zone by applying the relation in Fig. 1.

Although this may sound straightforward, the determination of residual stresses with diffraction techniques from the shift of line profiles is not a trivial task. The occurrence of (steep) composition- and stress-depth gradients requires special measurement strategies, correction procedures, or both to unravel the influences of composition and stress on the line profile shifts and the avoidance of artifacts knows as ghost stresses, which are the result of a variation of the depth range contributing to the diffracted intensity with a variation of the diffraction geometry (specifically the tilt angle $\psi$ in the $\sin ^{2} \psi$ method). In particular, the composition profile in expanded austenite can lead to ghost stresses exceeding $2 \mathrm{GPa}$; the effect of stress gradients is negligible as compared to the effect of a composition profile [8]. 
The lattice spacing determined in an X-ray diffraction experiment is the diffracted intensity-weighted average over the lattice spacing depth profile, $d_{\psi}^{h k l}(z)$ :

$$
\left\langle d_{\psi}^{h k l}\right\rangle=\frac{\int_{0}^{\infty} d_{\psi}^{h k l}(z) \cdot e^{-\mu k_{\psi}^{h k l} z} \cdot d z}{\int_{0}^{\infty} e^{-\mu k_{\psi}^{k k l} z} \cdot d z}
$$

with $\mu$, the (composition dependent) linear absorption coefficient of the applied X-radiation in the phase probed, and $k_{\psi}^{h k l}$, a factor that depends on the diffraction geometry.

For symmetric diffraction, use the following:

$$
k_{\psi}^{h k l}=\frac{2 \sin \theta \cos \psi}{\sin ^{2} \theta-\sin ^{2} \psi+\cos ^{2} \theta \sin ^{2} \psi \sin ^{2} \eta}
$$

where $2 \theta$ is the Bragg angle and $\eta$ denotes the rotation angle around the scattering vector (see Ref. [19]).

For asymmetric diffraction, use the following:

$$
k_{\psi}^{h k l}=\frac{1}{\cos \chi} \cdot\left(\frac{1}{\sin \alpha}+\frac{1}{\sin (\theta-\alpha)}\right)=\frac{\cos (\theta-\alpha)}{\cos \psi} \cdot\left(\frac{1}{\sin \alpha}+\frac{1}{\sin (\theta-\alpha)}\right)
$$

where $\chi$ is the rotation angle around the $\Psi$-axis and $\alpha$ is the grazing incidence angle. The effective $\psi$ angle is related to the effective $\chi$ angle by:

$$
\cos \psi=\cos \chi \cdot \cos (\theta-\alpha)
$$

\section{SYMMETRIC X-RAY DIFFRACTION AND PROFILE RECONSTRUCTION}

Over the years, several procedures for unraveling the contributions of stress and composition on the lattice spacing and retrieving stress and composition profiles with X-ray diffraction have been applied. A successful evaluation method to avoid ghost stresses is the reconstruction of lattice spacing-depth profiles, $d_{\psi}^{h k l}(z)$, for various values of constant $\psi$ from measured lattice spacing-depth profiles, $\left\langle d_{\psi}^{h k l}(z)\right\rangle$, and thereafter evaluation of the $d_{\psi}^{h k l}-\sin ^{2} \psi$ dependence at various depths to calculate the stress-depth, $\sigma_{/ /}(z)$, and strainfree lattice spacing depth, $d_{\varepsilon=0}^{h k l}(z)$, profiles $[8,20]$. In this method different depths are reached by successive layer removal with (electrochemical) polishing. The redistribution of stresses that occurs under this destructive layer removal to restore the force and momentum equilibrium can be straightforwardly accounted for [21]. An example of the result of this measurement and evaluation strategy is shown in Fig. 5 for three carburized AISI 316 specimens (for details, see the caption and Ref. [22]). Clearly, the results in Fig. 5 show that there is a direct relation between the amount of carbon dissolved and the elastic residual stresses achieved, which amount up to $2.7 \mathrm{GPa}$ in compression at the outer surface for the specimen with the highest carbon content.

Similar measurements and evaluations were also performed for nitrided and nitrocarburized AISI 316 stainless steel [1]. Recognizing the considerably higher interstitial solubility of nitrogen as compared to carbon and leading to a larger associated lattice expansion (see Fig. 2), the compressive residual stresses in expanded austenite containing nitrogen are expected to exceed those reached in carbon-stabilized expanded austenite. By probing the $\{200\}$ family of lattice planes applying the XECs of austenitic stainless steel, compressive stresses of 7 to $8 \mathrm{GPa}$ were obtained. Recent insight in the anomalous 
FIG. 5

Depth profiles of (a) strain-free lattice spacing, $d_{\varepsilon=0}^{200}$, and (b) residual stress, $\sigma_{/ /}$, for AISI 316 specimens carburized in $\mathrm{CO} / \mathrm{H}_{2}$ gas mixtures for the indicated $\mathrm{CO}$ contents (details in legend). Profiles were determined with $\mathrm{X}$-ray diffraction analysis combined with successive sublayer removal. Profiles are corrected for ghost stress effects, assuming a constant linear absorption coefficient, and for stress relaxation by successive sublayer removal. Inset shows cross-sectional reflected light micrographs in the expanded austenite zone, which was attempted to be kept at the same thickness for the three carburizing conditions [22].

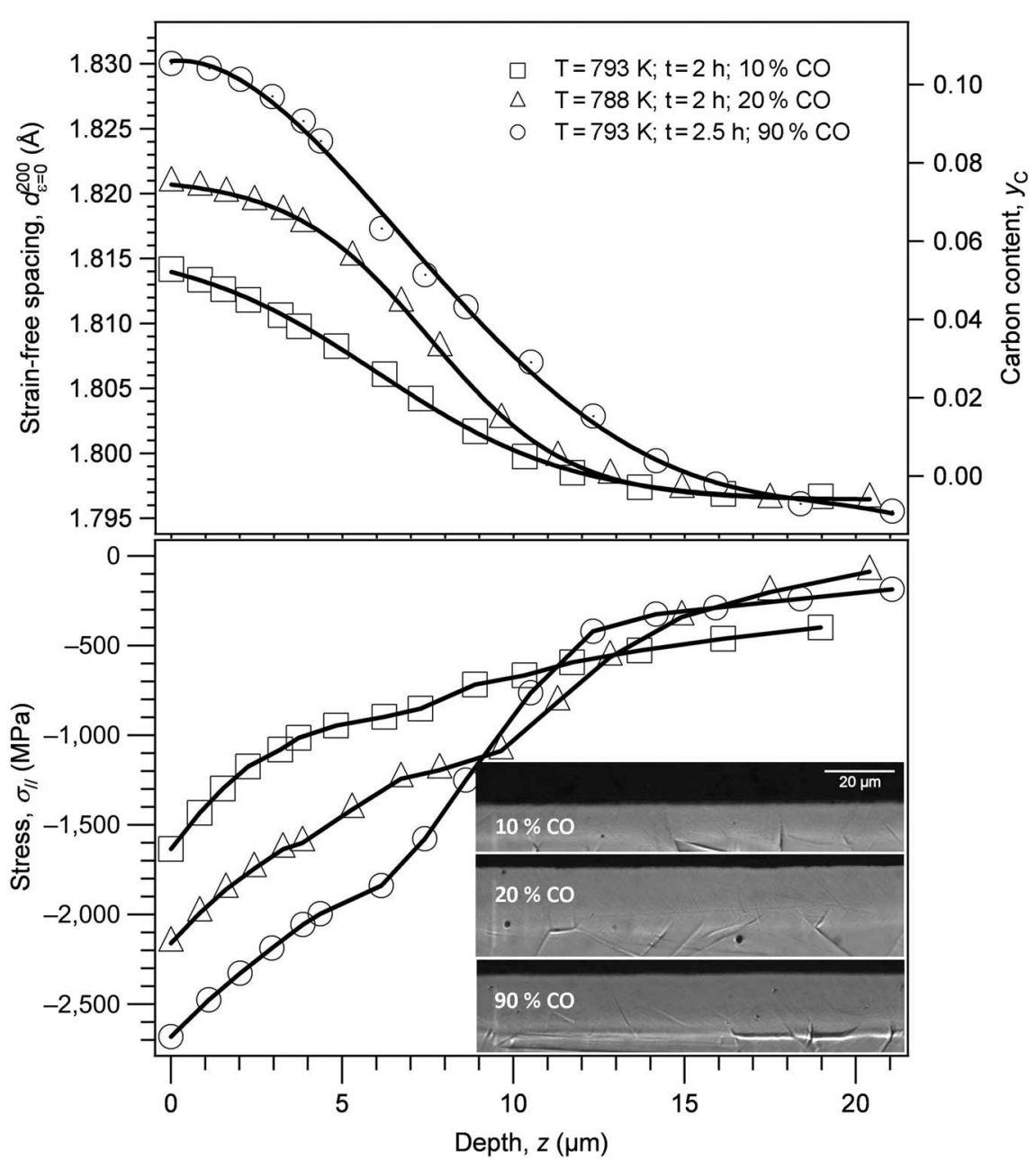

shift of, in particular, the 200-line profile of nitrogen-stabilized expanded austenite [23] implies that probing $\{200\}$ lattice planes for this case will lead to erroneous results. The reason for this is the colossal lattice expansion, which leads to strains that exceed the yield stress and plastic deformation in a large part of the expanded austenite zone. Such plastic deformation leads to lattice rotation (and thus a change in texture), as well as nonlinearity of the elastic behavior, which implies a change of the effective (X-ray) elastic constants. This phenomenon is most pronounced for $\{200\}$ and hardly affects $\{111\},{ }^{5}$ wherefore a discrepancy is found between results obtained on $\{111\}$ and $\{200\}$ lattice planes. Generally, probing $\{200\}$ leads to an overestimation of the residual stress value in nitrogen-containing expanded austenite, due to the net effect of the anomalously large line shift and modified elastic constant in deformed austenite.

${ }^{5}$ Normally, for X-ray residual stress analysis a $\{h k /\}$ line profile at a high Bragg angle is preferred to achieve the highest accuracy in assessing the peak shift. For expanded austenite, 111 and 200 are often the only available line profiles because of broad peaks (associated with the concentration profile) and low intensities (plastic deformation-induced lattice rotation toward $<100>$ and $<111>$ ). 


\section{ENERGY-DISPERSIVE SYNCHROTRON X-RAY DIFFRACTION}

Energy-dispersive synchrotron X-ray diffraction using the scattering-vector method [19] was applied for the nondestructive analysis of (part of) the residual stress and composition profile in a $14 \mu \mathrm{m}$-thick expanded austenite zone obtained by nitriding of AISI 316. In this energy-dispersive approach, the depth-resolved analysis relies on rotation over an angle $\eta$ about the scattering vector, while keeping the Bragg angle, $2 \theta$, constant (see Eq 4). The shift in the lattice spacing follows from the shift in the energy where the $\{h k l\}$ diffracts. This measurement is done for fixed values of the tilt angle $\psi$. The measured lattice spacing is arbitrarily assigned to the information depth, $\tau$, i.e., the diffracted intensity weighted depth:

$$
\tau=\langle z\rangle=\frac{\int_{0}^{\infty} z \cdot e^{-\mu k_{\psi}^{h k l} z} \cdot d z}{\int_{0}^{\infty} e^{-\mu k_{\psi}^{h k l} z} \cdot d z}
$$

It can be straightforwardly proven that the lattice spacing measured at an exposed surface $\left\langle d_{\psi}^{h k l}\right\rangle$ only corresponds to $d_{\psi}^{h k l}(\tau)$ if $d_{\psi}^{h k l}(z)$ is a linear function of $z$. Generally, for a nonlinear $d_{\psi}^{h k l}(z),\left\langle d_{\psi}^{h k l}\right\rangle \neq d_{\psi}^{h k l}(\tau)$. The results obtained with this approach are shown in Fig. 6 and demonstrate that nondestructive lattice spacing profiles for the various $\psi$ are obtained

FIG. 6 (a) Lattice spacing measurements obtained from energy-dipersive synchrotron X-ray diffraction for constant $2 \theta$, various fixed values of $\psi$. For each $\psi$ value the variation in information depth was achieved by a rotation $\eta$, about the diffraction vector (see Eq 4). (b) $\sin ^{2} \psi$ plot interpolated in (a) at $\tau=4 \mu \mathrm{m}$. (c) Interpolation for the strain-free direction in (b) yields the nitrogen content, $\mathrm{y}_{\mathrm{N}}$, while the slope gives the stress, $\sigma_{/ /}[24]$. The specimen was nitrided at $713 \mathrm{~K}$ in $\mathrm{NH}_{3}$ for $14 \mathrm{~h}$.

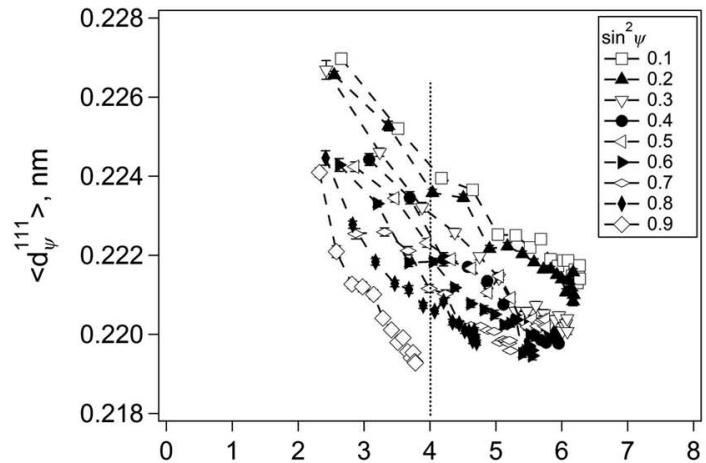

(a)

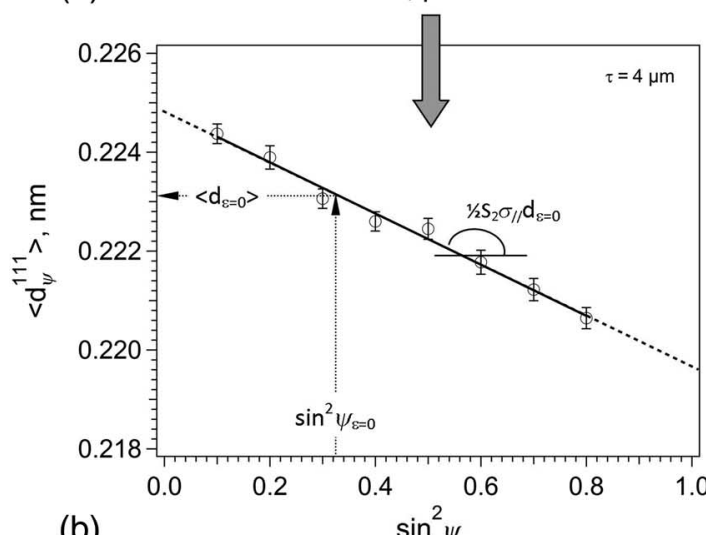

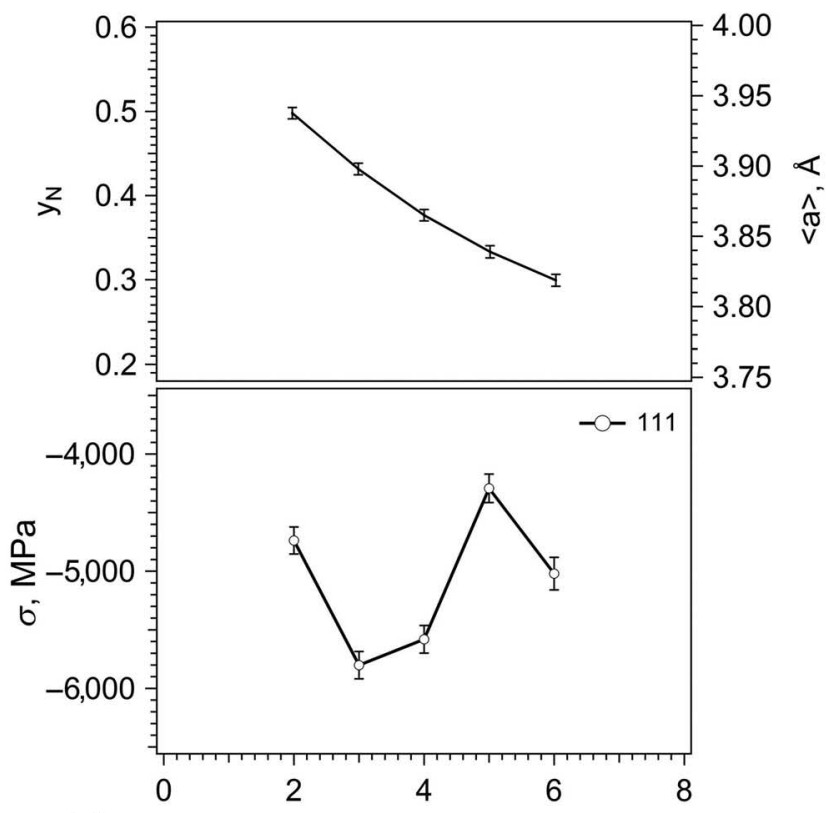

(c)

$\tau, \mu \mathrm{m}$ 
(see Fig. 6a). Interpolation among the data at $\tau=4 \mu \mathrm{m}$ provides an excellent linear dependence of $\left\langle d_{\psi}\right\rangle$ on $\sin ^{2} \psi$ (see Fig. $6 \mathrm{~b}$ ), the slope of which is proportional to the elastic stress $\sigma_{/ /}$(see Fig. $5 d$ ), while interpolation for the strain-free direction gives the strain-free lattice spacing (see Fig. 5c). Even though this method has the advantage of being nondestructive, a major disadvantage is that it can only provide information on the stress- and composition-profiles for a depth maximally corresponding to half the thickness of the expanded austenite zone [24].

\section{GRAZING-INCIDENCE X-RAY DIFFRACTION WITH CONSTANT INCIDENCE}

\section{ANGLE}

Grazing incidence X-ray diffraction was applied to limit the depth range and its variation with effective $\psi$, over which diffracted intensity is weighted, thus limiting the ghost stress effects [14]. For the case of investigating the $\{111\}$ lattice planes in expanded austenite with $\mathrm{Cr} \mathrm{K}_{\alpha}$ radiation applying a grazing incidence angle of $2.0^{\circ}$, the information depth varies from 0.36 to $0.15 \mu \mathrm{m}$ when $\sin ^{2} \psi$ changes from 0 to 0.8 (see Fig. $7 \mathrm{a}$ ).

Still the ghost stress was calculated to reach about $350 \mathrm{MPa}$ for the steepest part in the composition profile [14]. The composition-depth profile and (elastic) residual stress-depth profile obtained by this method is shown in Fig. 7c. The expanded austenite zone has a thickness of $13 \mu \mathrm{m}$ (see Fig. 7b) and the nitrogen content close to the surface amounts to

FIG. 7 (a) Variation of information depth with effective tilt angle $\psi$ for grazing incidence $X$-ray diffraction for the combinations given in the legend. (b) Hardness-depth profile for the investigated specimen. (c) Composition-depth and stress-depth profiles assigned to the (shallow) average information depth for the investigated $\sin ^{2} \psi$ range 0-0.8 combined with successive layer

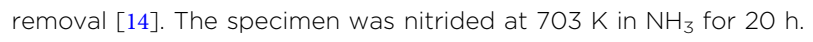
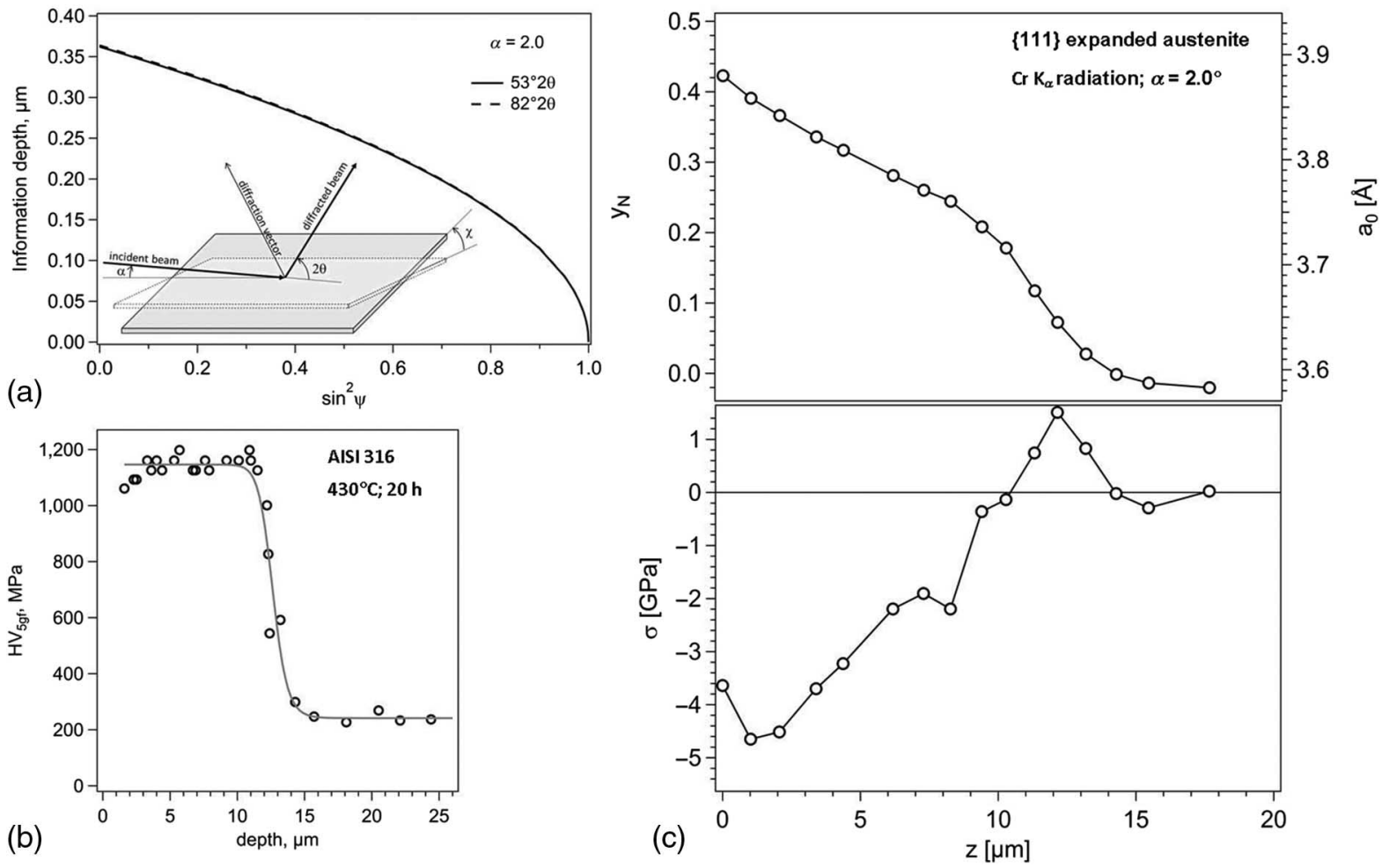

(b)

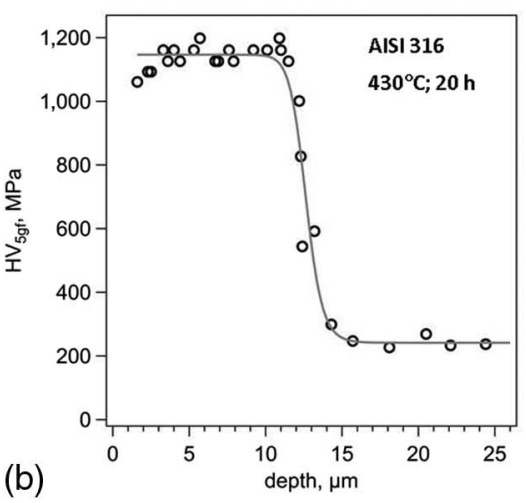

c)

$\mathrm{z}[\mu \mathrm{m}]$ 
FIG. 8

Relation between residual stress in Fig. 7c (full circles) with the composition-induced lattice strain, as obtained from the composition/strain-free lattice spacing profile in

Fig. 7c. The data for the carburized specimens in Fig. 5 are represented by the open triangles and show the same slope for the dependence of stress on chemically imposed strain.

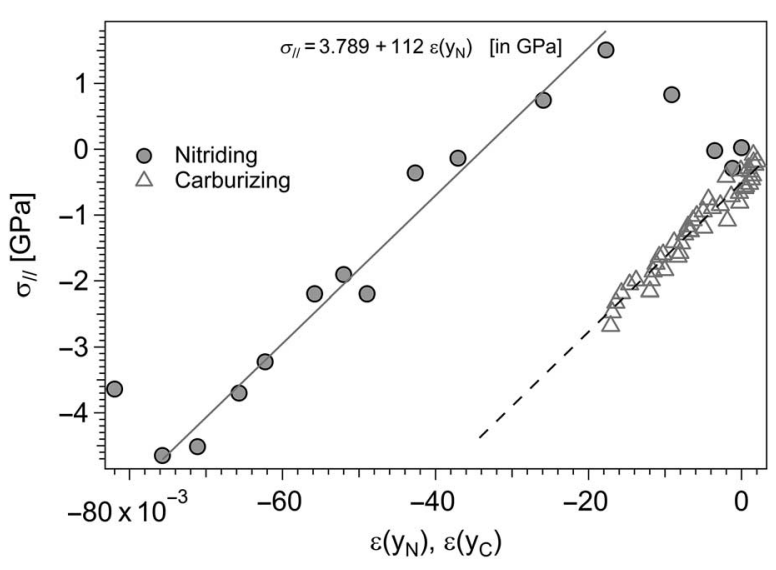

$\mathrm{y}_{\mathrm{N}}=0.42$, while the residual stress is maximally $4.6 \mathrm{GPa}$ at a few $\mu \mathrm{ms}$ below the surface. It appears that a tensile stress is reached in the expanded austenite zone close to the unaffected austenite. As was mentioned in Ref. [14], in this region the $\sin ^{2} \psi$ dependencies were not linear, but slightly curved. Also, this is the region where (tensile) ghost stresses of $350 \mathrm{MPa}$ arise, implying that the quantitative value of the apparent tensile stress can be flawed. Comparing the determined stress values in Fig. 7c to the (elastic) compressive strain profile calculated from the composition profile in Fig. 7c (as evaluated from the strain-free lattice parameter profile), a linear relation is obtained between stress and strain (see Fig. 8). This linear relation includes the tensile value close to the case/core transition, suggesting that tensile stresses in this region of the expanded austenite zone would be consistent with the stress-strain dependence.

Assuming that all composition-induced strain is accommodated elastically, the slope of the linear relation in Fig. 8 could be predicted from the Young's modulus, $E$, and the Poisson constant, $\nu$ :

$$
\sigma_{\|}=\frac{E}{1-\nu} \cdot \varepsilon
$$

Inserting $E=200 \mathrm{GPa}$ and $\nu=0.32$ yields $294 \mathrm{GPa}$ for the slope in Fig. 8. Experimentally, the slope amounts to less than $38 \%$ of this predicted value. This leads to the conclusion that either the elastic constants of expanded austenite are different from those for austenite, that not all strain is accommodated elastically, or both. Both explanations are likely to apply. It has been suggested on the basis of nanoindentations that because of the incorporation of high amounts of interstitials in austenite, the elastic constants change [25]. ${ }^{6}$ Also, the occurrence of plastic deformation in expanded austenite was observed by several research groups [6,16,17]. For comparison, the data of Fig. 5 is included in Fig. 8. Evidently, the same slope relating stress and strain applies for nitrogen- and carbonstabilized expanded austenite, as reflected by the dashed line obtained by a parallel shift of the drawn line for the nitrided specimen.

${ }^{6}$ Note that this also applies for the stress values obtained using the XECS applying for austenite. 


\section{GRAZING-INCIDENCE X-RAY DIFFRACTION AT VARIABLE INCIDENCE ANGLE AND CONSTANT INFORMATION DEPTH}

Recognizing that the stress profile in Fig. 7 is reflecting only the elastically accommodated strain and that this strain scales with the composition (see Fig. 8), it could be suggested that the elastic stresses in expanded austenite can be modified by modifying the composition profile. This was attempted by removing nitrogen from expanded austenite through an annealing treatment in pure hydrogen, called de-nitriding. In this de-nitriding stage, hydrogen supplied by the gas removes nitrogen in solid solution under the development of ammonia gas at the specimen surface. Fig. $9 \mathrm{~b}$ demonstrates that this treatment indeed leads to a modification of the nitrogen-depth profile, as shown by GD-OES, such that a plateau of nitrogen remains over the expanded austenite zone.

This de-nitriding leads to only a modest modification of the hardness profile over the hardened zone (see Fig. 9c). For the determination of residual stresses for this particular case, the influence of ghost stresses was attempted to be minimized by keeping the information depth small, by applying grazing incidence angles of $3^{\circ}, 7^{\circ}$, and $12^{\circ}$ (see Fig. 9a; gray markers and dashed lines). For the nitrided specimen, an increase of the grazing incidence angle leads to a shift of the $\sin ^{2} \psi$ relation to lower lattice spacings, reflecting the increase in information depth with incidence angle and the gradient in nitrogen content (see Fig. 9b). For the subsequently de-nitrided specimen, the lattice spacing is reduced dramatically, and the slope of

FIG. 9 (a) Grazing incidence $X$-ray diffraction $\sin ^{2} \psi$ plots at three fixed grazing incidence angles $3^{\circ}, 7^{\circ}$, and $12^{\circ}$, performed for nitrided AISI 316 ( $713 \mathrm{~K}$ in $100 \% \mathrm{NH}_{3}$ for $16 \mathrm{~h}$ ) and subsequently de-nitrided ( $708 \mathrm{~K}$ in $100 \% \mathrm{H}_{2}$ for $2 \mathrm{~h}$ ). Inset shows the dependence of the information depth $\tau$ on $\sin ^{2} \psi$. (b) GD-OES nitrogen depth profiles of nitrided and subsequently de-nitrided specimens.

(c) Corresponding hardness-depth profiles show only a small decrease in hardness on de-nitriding (data from Ref. [26]).
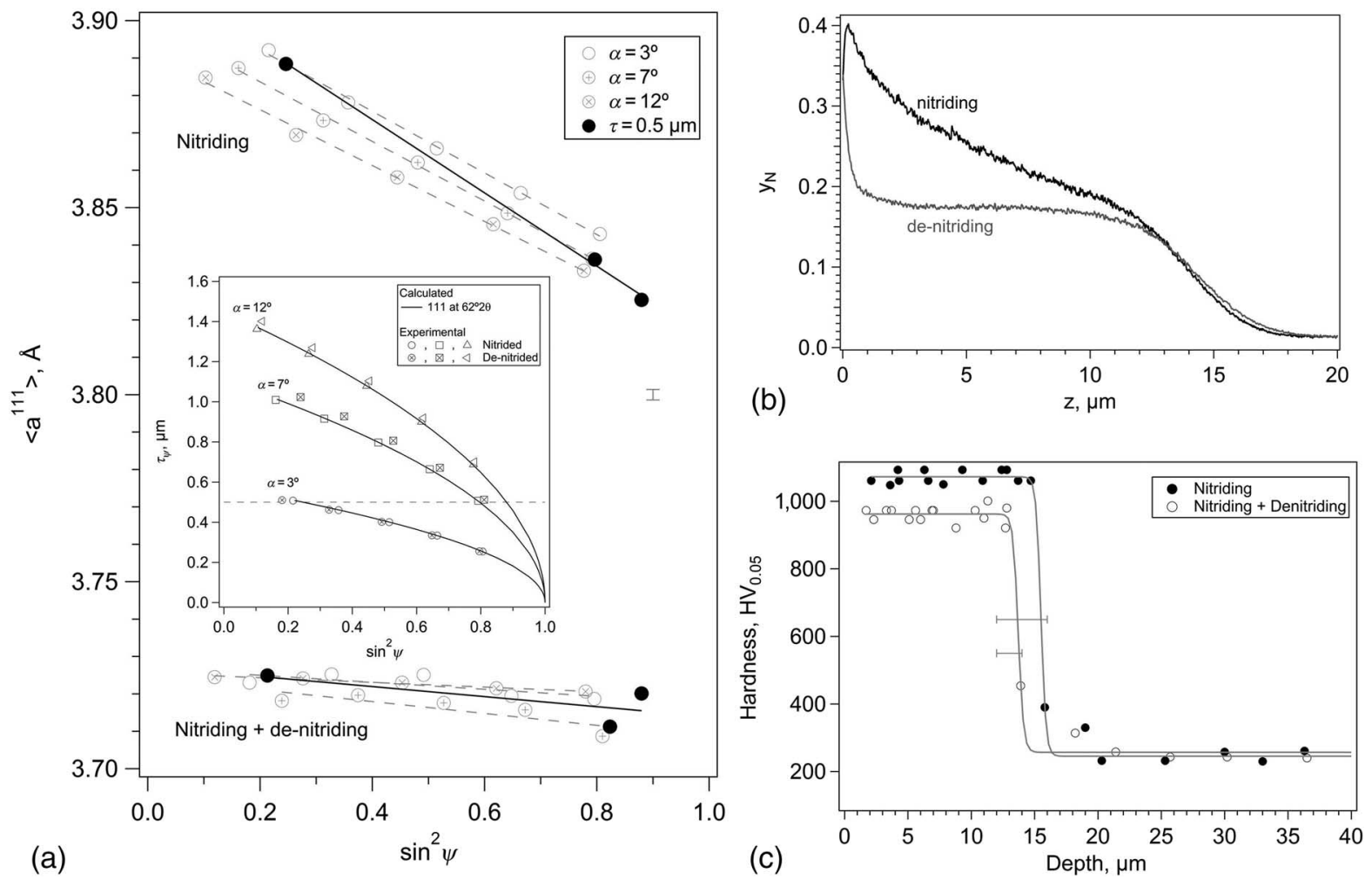

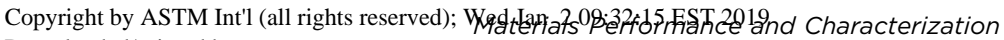


the $\sin ^{2} \psi$ relation indicates an important reduction of the residual stress in expanded austenite. The inset in Fig. 9a shows the variation of the information depth with $\sin ^{2} \psi$ and indicates that ghost stresses cannot be avoided in the $\sin ^{2} \psi$ method if the incidence angle is fixed. The inset also shows that by combining various incidence angles, the information depth can be maintained at a constant value, as indicated by the horizontal dashed line at $\tau=0.5 \mu \mathrm{m}$. The lattice spacings corresponding to this information depth for the investigated incidence angles can be obtained by inter- and extrapolation in the $\sin ^{2} \psi$ plots for constant $\alpha$ and are given by the black markers in Fig. 9a. The thus constructed $\sin ^{2} \psi$ relations (drawn black lines in Fig. 9a) give $-5 \mathrm{GPa}$ for the nitrided condition to $-100 \mathrm{MPa}$ (virtually zero stress) for the subsequently de-nitrided condition. Evidently, removing the composition profile in the first $12 \mu \mathrm{m}$ of the expanded austenite zone by de-nitriding leads to removal of elastic residual stress at the surface [26]. Most likely the virtually zero-stress state extends to the entire zone where the nitrogen content is constant (see Fig. 9b), but this has so far not been investigated. Since the hardness profile was only slightly changed by removing about one third of all nitrogen (see Fig. 9c), it is concluded that the hardness increase in expanded austenite is caused by the combination of the remaining level of nitrogen and the plastic deformation introduced.

To further verify whether the elastic residual stress can be tailored in between the two extrema in Fig. 9, a series of annealing experiments (after nitriding) in gases with different ratios of $\mathrm{NH}_{3}$ and $\mathrm{H}_{2}$ were performed. From equilibrium studies it is known that the nitrogen content in homogenous, thin stainless steel foils can be accurately adjusted by equilibrating the which is foil in a $\mathrm{NH}_{3} / \mathrm{H}_{2}$ gas mixture. The relation between the nitrogen content, $\mathrm{y}_{\mathrm{N}}$, and the nitrogen activity, $\mathrm{a}_{\mathrm{N}}$, which is the thermodynamic property associated with the gas composition and linearly proportional to the nitriding potential, $\mathrm{K}_{\mathrm{N}}=\mathrm{pNH}_{3} / \mathrm{pH}_{2}^{3 / 2}$, is shown in Fig. 10a. The de-nitriding gas compositions during annealing were adjusted according to the indicated dashed lines, to obtain a range of nitrogen contents. The information depth during lattice strain measurement was kept constant at $0.5 \mu \mathrm{m}$ by choosing the combinations of grazing incidence angle and $\sin ^{2} \psi$ value (by $\chi$ rotation, see inset in Fig. 7a) as given in Fig. 10b. The $d_{\psi}$ versus $\sin ^{2} \psi$ relations for the various de-nitriding steps are shown in Fig. 10c for the chosen $\mathrm{K}_{\mathrm{N}}$ (corresponding to $\ln \mathrm{a}_{\mathrm{N}}$ ). As follows from the stepwise decrease of the lattice parameter in the strain-free direction, $\sin ^{2} \psi_{\varepsilon=o}$ (see dashed vertical line in Fig. 10c), the nitrogen content can be tailored by adjusting the gas composition. Moreover, the gradual change in slope indicates that the stress (as determined to be close to the surface) can be tailored accordingly. The relation between the stress and the nitrogen content, as determined from the data in Fig. 10c, is given Fig. 11. It is noted that, apart from the $\mathrm{y}_{\mathrm{N}}$ obtained after full de-nitriding (pure $\mathrm{H}_{2}$ ), the nitrogen contents determined are systematically lower than reflected by Fig. 10a, which applies for stress-free thin foils. The discrepancy could be a consequence of the coupling between stress and composition, i.e., compressive stress reduces the solubility of nitrogen. Also, it is observed that the relation between stress and nitrogen content is not linear, as was anticipated on the basis of Fig. 8, and that the stress decreases steeply in the first de-nitriding step, i.e., from $y_{N}=0.46$ to $y_{N}=0.41$. In order to explain this, numerical modeling of composition and stress profiles is described in the next section.

\section{Prediction of Residual Stress in Expanded Austenite}

In the literature, various attempts to predict the composition profile over the expanded austenite layer have been published. Roughly two approaches can be recognized to explain 
FIG. 10 (a) Relation between nitrogen activity, $a_{N}$, and the nitrogen content in homogeneous stress-free expanded austenite foils. (b) Variation of information depth, $\tau$, with $\sin ^{2} \psi$ for various grazing incidence angles, $\alpha$, at a Bragg angle corresponding to \{111\} investigated with $\mathrm{Cr} \mathrm{K}_{\alpha}$ radiation, combining various incidence angles enabling a constant information depth (horizontal dashed line). (c) Lattice spacing versus $\sin ^{2} \psi$ (see [b]) for various $\mathrm{a}_{\mathrm{N}}$ (see [a]), as realized by $\mathrm{K}_{\mathrm{N}}=\mathrm{pNH}_{3} / \mathrm{pH}_{2}{ }^{3 / 2}$. Interpolation in the strain-free direction, $\sin ^{2} \psi_{\varepsilon=0}$, provides the nitrogen content, $\mathrm{y}_{\mathrm{N}}$ (see Fig. 11).
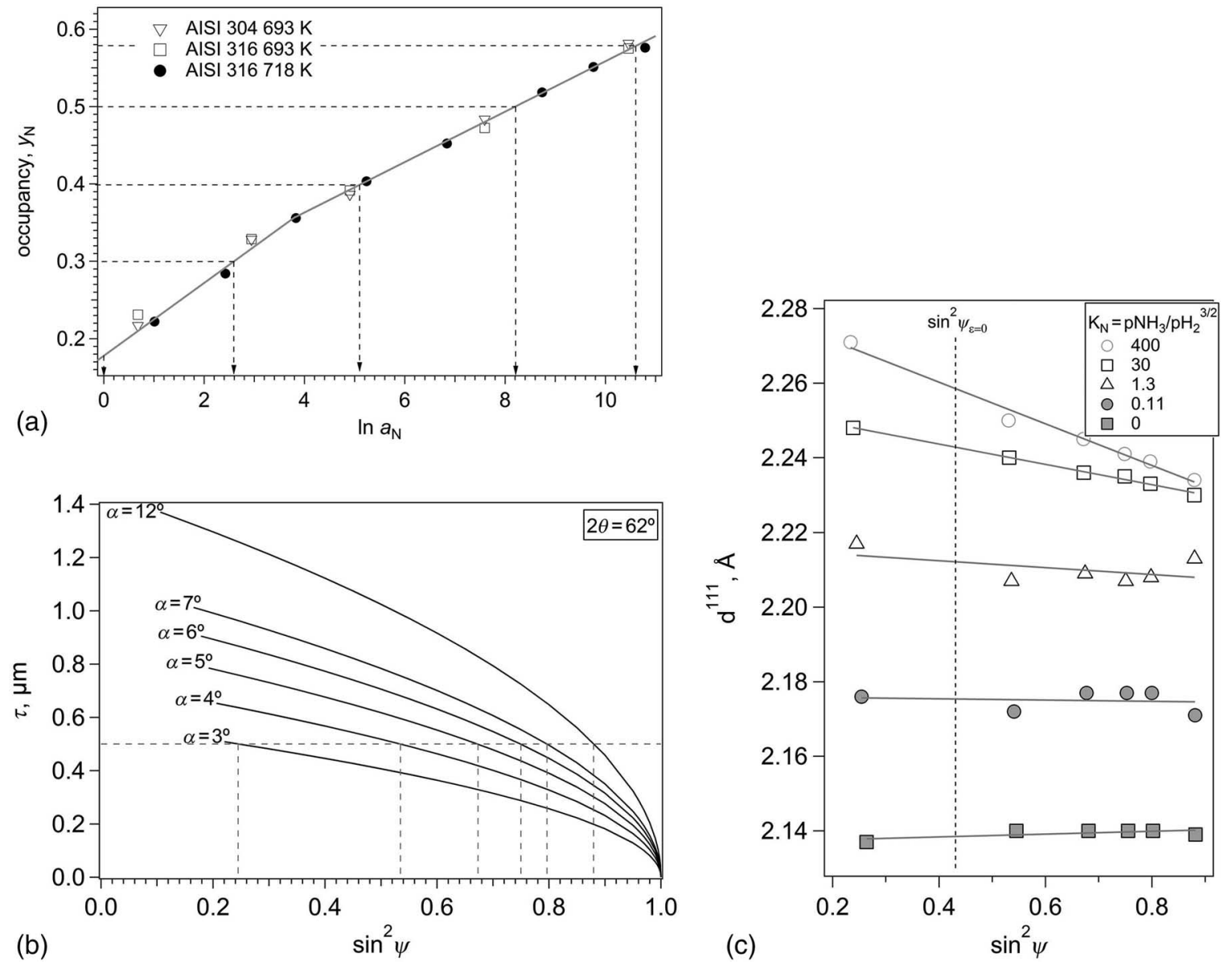

FIG. 11

Relation between stress, $\sigma_{/ /}$, as determined from the slopes in Fig. $10 \mathrm{c}$ and the nitrogen content, $\mathrm{y}_{\mathrm{N}}$, as determined for the strain-free direction, $\sin ^{2} \psi_{\varepsilon=0}$, in Fig. 10c. Gradual de-nitriding leads to a step-wise reduction of the compressive residual stress [37].

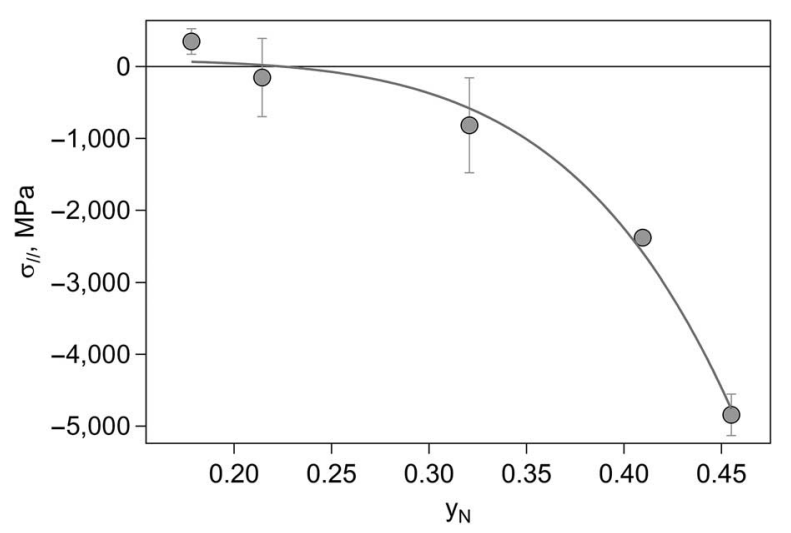

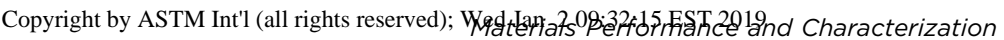

Downloaded/printed by

Technical University of Denmark (Technical University of Denmark) pursuant to License Agreement. No further reproductions authorized. 
the shape of the nitrogen (or carbon) concentration profile: (i) a composition-dependent diffusivity of the interstitials $[27,28]$, or (ii) a gradient in the trapping-detrapping of interstitials by trap sites in combination with a constant diffusivity [29]. Somers and Christiansen [30] were the first to pinpoint the idea that the role of stress on the evolution of the composition profile in this system can be substantial. Only few models include the role of the elastic residual stress distribution $[15,31,32]$ and the cross-correlation between stress and composition by considering the influences of stress on thermodynamics (nitrogen solubility) and diffusion kinetics (stress-enhanced diffusion).

The diffusive flux, $J$, induced by a one-dimensional gradient in the chemical potential, $\mu_{N}$, is defined as:

$$
J=-M_{N} c_{N} \frac{\partial \mu_{N}}{\partial z} \quad \text { where } \quad M_{N}=\frac{D_{N}}{R \cdot T}
$$

with $M_{N}$ as the mobility of nitrogen, $D_{N}$ as the diffusivity of nitrogen, $R$ as the gas constant, and $T$ as temperature. For a solid solution the chemical potential obeys:

$$
\mu_{N}\left(a_{N}, T\right)=\mu_{N, 0}+R T \cdot \ln \left(a_{N}\right)-\bar{V}_{N} \cdot \sigma_{H}
$$

where $a_{N}$ is the activity of nitrogen in solid solution, $\bar{V}_{N}$ is the partial molar volume of nitrogen, and $\sigma_{H}$ is the hydrostatic stress component (i.e., pressure). The activity of nitrogen is defined with reference to $\mathrm{N}_{2}$ at atmospheric pressure, which for a gas mixture of ammonia and hydrogen with nitriding potential $K_{N}=\frac{p_{N H_{3}}}{p_{H_{2}}^{3 / 2}}$ (with $p_{j}$ as the partial pressure of component j) equals:

$$
a_{N}=K_{T} \cdot K_{N}
$$

where $K_{T}$ is the equilibrium constant for ammonia dissociation at temperature $T$.

Substituting Eqs 10 and 11 in Eq 9, considering a concentration-dependent diffusion coefficient, leads to a nonlinear equation with gradients in composition, stress, and temperature in the thickness direction [15]. Consequently, the model applied in the present work is a multi-physics model, including coupling of heat conduction, solid state diffusion, and mechanical equilibrium equations over the specimen thickness $[15,33]$.

The volumetric expansion due to the interstitially dissolved nitrogen atoms is described with a chemical (composition-induced) strain in one of three principal directions. If the chemical strain, $\varepsilon_{i j}^{c h}$, is assumed isotropic, it holds:

$$
\varepsilon_{i i}^{c h}=\frac{V(c)^{1 / 3}-V_{r e f}^{1 / 3}}{V_{r e f}^{1 / 3}} \quad \text { and } \quad \varepsilon_{i j}^{c h}=0 \text { for } i \neq j
$$

where the concentration-dependent volume of the iron lattice $V\left(y_{N}\right)$ is straightforwardly derived from Fig. 1. For the expanded austenite zone, a state of plane stress parallel to the surface can be assumed. Then, the elastic strain normal to the surface becomes:

$$
\varepsilon_{33}^{e l}=-\frac{\nu\left(\varepsilon_{11}^{e l}+\varepsilon_{22}^{e l}\right)}{(1-\nu)}
$$

In the case of pure plastic strain, the relation comes from plastic incompressibility: 


$$
\varepsilon_{33}^{p l}=-\left(\varepsilon_{11}^{p l}+\varepsilon_{22}^{p l}\right)
$$

In addition to this elastoplastic state of plane stress, a von Mises yield criterion and isotropic work hardening were assumed. Recognizing that austenite, as a crystalline material, is strongly both elastically and plastically anisotropic, this is a simplification of the actual state of stress within individual grains, which depends on crystallographic orientation but also on interaction between the grains.

Jespersen, Hattel, and Somers [15] were the first to include the occurrence of plasticity for residual stresses beyond the composition-dependent yield stress and demonstrated a satisfactory agreement between the level of elastic residual stress of $-5 \mathrm{GPa}$ at the surface, as shown in Figs. 6, 7, 8, and 11. The explicit finite-difference model presented in Ref. [15] was modified to an implicit finite-difference model to allow inverse modeling [33] and consists of a thermal, a thermochemical, and a mechanical part. The yield stress of expanded austenite, which is important in the von Mises criterion, has for obvious reasons not been determined experimentally and was estimated from the relations between hardness and composition on one side and the extrapolation of the relation between yield stress and hardness on the other side [15]. Hence, a maximum yield stress of $4 \mathrm{GPa}$ in uniaxial tension was estimated. Since uniaxial tension only differs by a hydrostatic state of stress from biaxial compression within the plane perpendicular to the tensile direction, this implies that the yield stress in plane stress is $-4 \mathrm{GPa}$.

To calculate the nitrogen concentration- and stress-depth profiles, the only input parameters are temperature, nitriding potential, nitriding time, and yield stress. All other parameters were taken as those determined for homogenous stress-free thin foils (see Fig. 1 for the lattice expansion leading to chemical stress according to Eq 12, the equilibrium concentration from Fig. 10a, and the concentration-dependent diffusivity of nitrogen in expanded austenite from Ref. [34]). No fit parameters were used at all. More details will be provided in a forthcoming publication [35]. The purpose of the modeling attempts is not to obtain a perfect fit between experimental and numerical modeling, which could be straightforwardly achieved by introducing a wealth of fit parameters, but rather to explore the various influences of and in particular the role of plastic deformation. Fig. 12a presents the concentration and elastic residual stress profiles calculated for nitriding AISI 316 at $440^{\circ} \mathrm{C}$ for $4 \mathrm{~h}, 8 \mathrm{~h}$, and $16 \mathrm{~h}$ in pure ammonia. Clearly, the surface concentration of nitrogen in expanded austenite increases with treatment time, and the concentration and stress profiles penetrate gradually into the austenite. The increase of the surface concentration with time is the outcome of a competition between the flux of nitrogen atoms arriving at the surface by ammonia dissociation and the flux of nitrogen atoms leaving the surface by inward diffusion. A comparison of the concentration- and stressprofiles to those in Fig. 7b shows a qualitative agreement for the nitrogen concentration profile. The calculated stress-depth profile is characterized by a plateau stress value of -4.1 GPa, which was not found in the measured profile in Fig. 7b. Nevertheless, the magnitude of the maximum compressive stress is in good correspondence with the experimental values. The occurrence of a constant elastic stress is attributed to the assumption of constant yield stress of $4 \mathrm{GPa}$ for nitrogen contents beyond $\mathrm{y}_{\mathrm{N}} \sim 0.1$. Perhaps the correspondence between calculated and measured residual stress profiles can be improved by considering the contribution of work hardening and an associated further increase of the yield strength. Fig. 12b shows how the strains are accommodated by the expanded austenite as elastic strains within the plane of the expanded austenite zone $\left(\varepsilon_{11}^{e l}=\varepsilon_{22}^{e l}\right)$ and 
FIG. 12

\section{Calculated composition-depth} and (elastic) residual stressdepth profiles for $4 \mathrm{~h}, 8 \mathrm{~h}$, and 16 h nitriding of AISI 316 at $713 \mathrm{~K}$ (a) and corresponding elastic strains within the plane of the expanded austenite zone $\left(\varepsilon_{11}^{\mathrm{el}}=\varepsilon_{22}^{\mathrm{el}}\right)$, the plastic strain parallel to the surface normal $\left(\varepsilon_{33}^{\mathrm{pl}}\right)$, and the thermal strain $\varepsilon^{\text {th }}$ as a consequence of a variation in thermal expansion coefficient with interstitial content (see

Fig. 4).
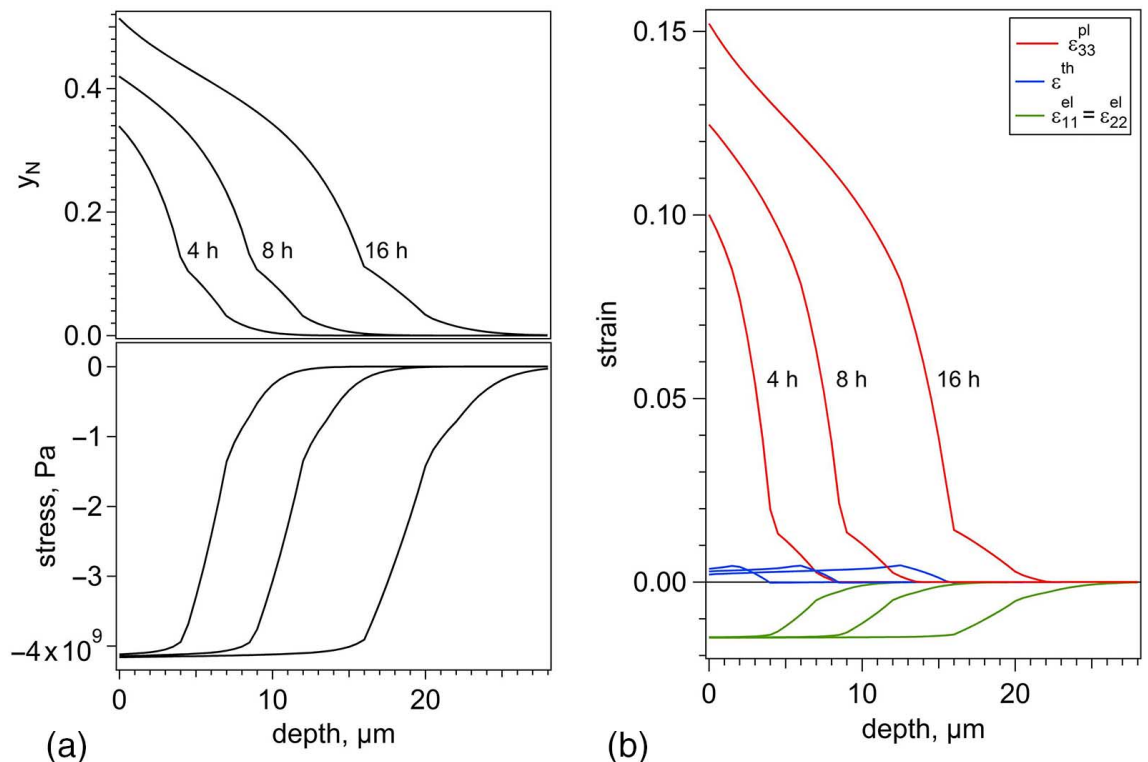

plastic strain in the direction perpendicular to the surface $\left(\varepsilon_{33}^{p l}\right)$. Evidently, substantial plastic strains are introduced by dissolving nitrogen. Comparing Fig. 12a and b leads to the conclusion that the continued uptake of nitrogen, which leads to an increase of the nitrogen content at the surface, is fully plastically accommodated. Fig. $12 \mathrm{~b}$ also shows the additional strains introduced on cooling from the treatment temperature to room temperature as a consequence of a variation of the linear expansion coefficient with the interstitial content (see Fig. 4). The decrease in thermal expansion coefficient with nitrogen content in expanded austenite will lead to an additional compressive strain parallel to the surface ( $\varepsilon^{\text {th }}$, particularly below the Curie temperature for the ferromagnetic expanded austenite. If the thermal strains are accommodated elastically, the thermal strain, $\varepsilon^{\text {th }}$ is added to $\varepsilon_{11}^{e l}=\varepsilon_{22}^{e l}$. Since the current model assumes the yield stress to be independent of temperature, no additional elastic accommodation of the strain is possible during cooling after nitriding. Consequently, the strain is accommodated plastically in the direction perpendicular to the surface (see the blue lines in Fig. 12b).

The lattice rotation associated with plastic strain was investigated for expanded austenite obtained by nitriding of AISI 316 for $8 \mathrm{~h}$ at $440^{\circ} \mathrm{C}$ with electron backscatter diffraction (EBSD), the results of which are shown in Figs. 13 and 14. For grains with their surface normal near $\langle 100\rangle$ (red grains in Fig. 13), relatively many unidentifiable locations were found close to the surface, as a consequence of excessive plastic deformation. For the grains with a surface normal close to $<111>$ (blue grains in Fig. 13), it was easier to investigate the lattice rotation due to plastic deformation over the entire case depth. Evidently, all investigated grains suffer from substantial plastic deformation, and the plastic deformation increases steeply on approaching the surface. In the vicinity of the surface an additional steep increase is observed, which is attributed to unconstrained plastic deformation by movement out of the plane of the surface. The corresponding rotation of the lattice depends on the slip systems, which are activated. For the presented 
FIG. 13 EBSD results of AISI 316 nitrided for $713 \mathrm{~K}$ for $8 \mathrm{~h}$ in pure $\mathrm{NH}_{3}$. Top row shows image quality maps (IQM); second row shows orientation image maps (OIM). For the locations of the arrows, the misorientations are given in Fig. 14; the rotation of the lattice is given in the inverse pole figures (IPF), starting in the unaffected AISI 316 for the white dots and moving toward increasingly darker dots.
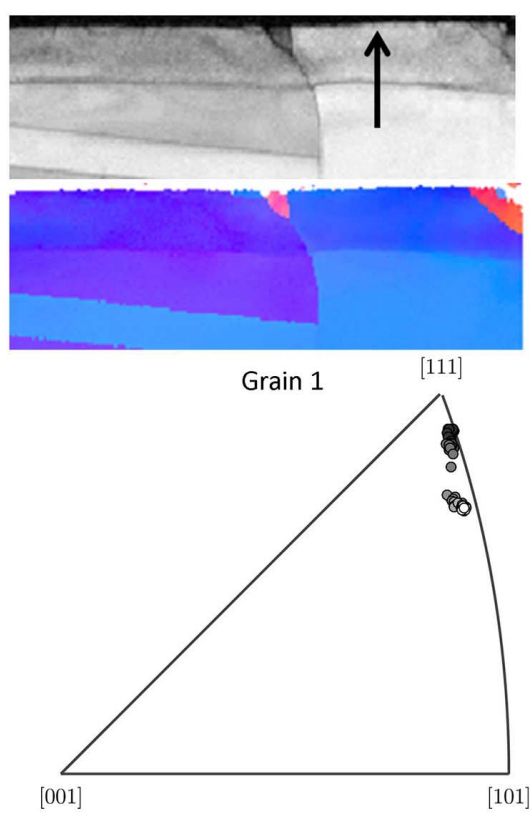
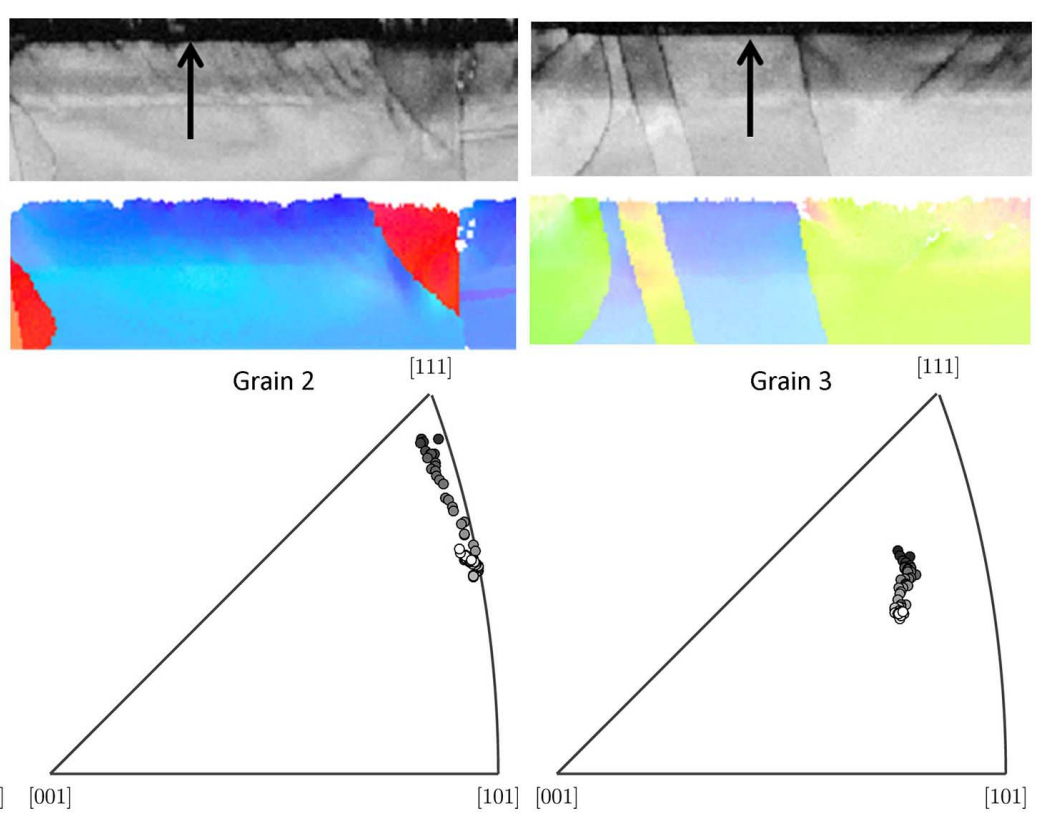

[101]
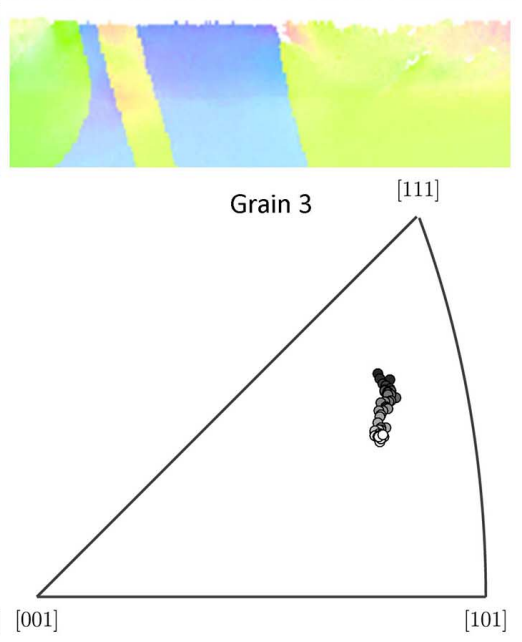

FIG. 14 Misorientation of the grains in Fig. 13 presented as a function of the depth below the surface (a); comparison of the experimental misorientation of Grain 3 with depth $\left(z_{\exp }\right.$ ) with the calculated plastic strain $\varepsilon_{33}^{\text {pl }}$ (see Fig. 12b) versus the depth $z_{\text {model. }}$

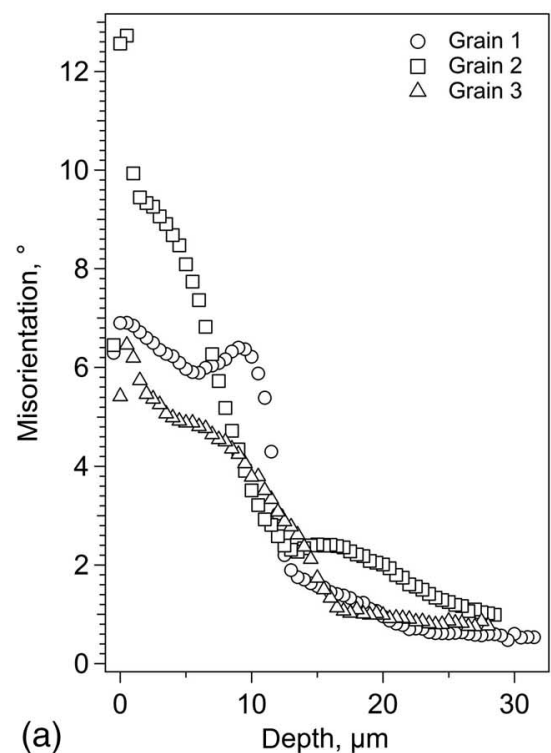

(a)

Depth, $\mu \mathrm{m}$

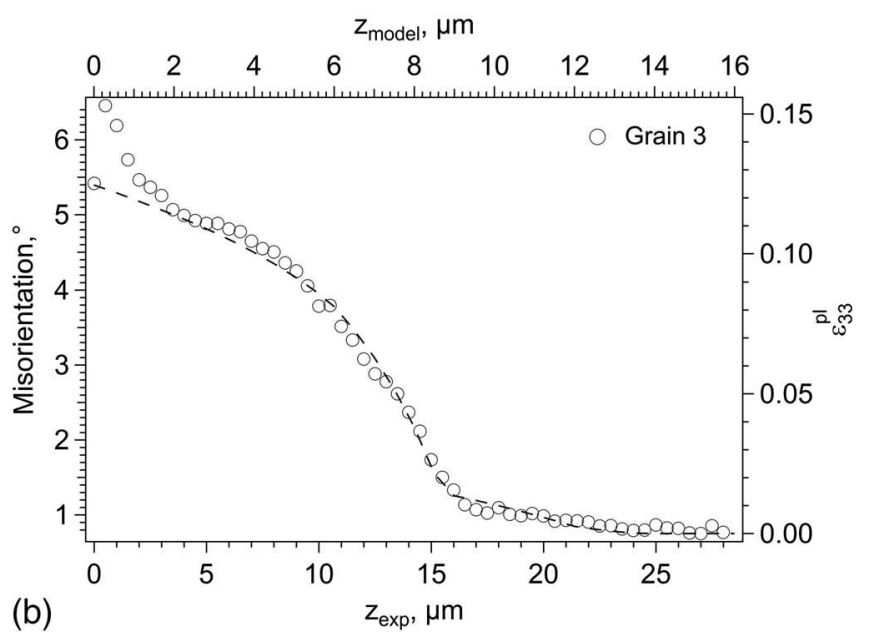

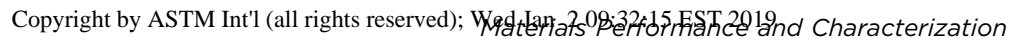


grain orientations, the surface normal rotates predominantly toward $<111>$ in agreement with earlier observations for expanded austenite grains of similar orientation by Templier et al. [17]. The results imply that in addition to a composition-depth profile and a stressdepth profile, a crystallographic texture-depth profile is also present. This has implications for the analysis of lattice strains (residual stress) with X-ray diffraction techniques, particularly if large information depths are applied. The consequences have, so far, not been investigated.

The quantitative misorientation profiles for the grains in Fig. 13 at the locations of the arrows are given in Fig. 14. Evidently, the lattice rotation expressed as the misorientation in Fig. 14a depends strongly on the original grain orientation. This is attributed to the plastic anisotropy of the f.c.c. lattice and the interaction with differently oriented neighboring grains. A comparison of the experimental misorientation with the calculated plastic strain perpendicular to the surface is given in Fig. 14b. Recognizing that the numerical model is a continuum model, Grain 3 was chosen for comparison, because its orientation is not too close to the boundary of the inverse pole figure (see Fig. 13). In Fig. 14b the vertical and horizontal scales for model and experiment were scaled as to obtain a satisfactory agreement between model and experiment. The discrepancy of the horizontal scales indicates that the diffusion-controlled growth conditions in model and experiment have been different. As a rule of thumb, the plastic strain expressed in percentage is twice the misorientation expressed in degrees, which corresponds roughly with the ratio of the vertical scales in Fig. 14b. The striking correspondence between the experimental and modeling results in Fig. $14 \mathrm{~b}$ is most encouraging. A better correspondence cannot be expected at this stage, because the model accounts for neither elastic anisotropy (which affects solubility [see Eq 10] and stress-induced diffusion [see Eq 9]) nor plastic anisotropy. Moreover, the change from constrained to unconstrained lattice rotation close to the surface was not accounted for either. This may explain the sudden increase in misorientation on approaching the surface.

The effect of de-nitriding on the stress distribution was modeled for the case of full nitriding, followed by de-nitriding down to plateau level, where $\mathrm{Cr}: \mathrm{N}=1: 0.9$. The results of this modeling attempt are shown in Fig. 15 and are represented by the drawn and dashed black lines. Analogous to Fig. 9b, the nitrogen level is reduced to what is called trapping level. Corresponding composition and stress profiles after partial de-nitriding are presented by the colored lines. For the elastic stress distribution after de-nitriding in $\mathrm{H}_{2}$ (drawn black line) a strong tensile stress is observed in the major part of the expanded austenite zone and a steep conversion from compression to tension on reaching the trapping-level. The results are interpreted as follows. Removing nitrogen from the strongly plastically deformed part of the expanded austenite zone firstly removes the elastically accommodated strain, along with reducing the nitrogen content. As demonstrated by the red lines in Fig. 15a and b, a small reduction in nitrogen content at the surface has a major effect on the compressive residual stress at the surface. As a consequence of plastic accommodation of the lattice expansion during nitriding, removal of more nitrogen than corresponding with an annihilation of the elastically accommodated compressive strain leads to tensile straining of the plastically deformed part (blue line in Fig. 15b). Eventually, the level of the yield strength is attained (green line in Fig. 15b), beyond which additional plastic strain is introduced. Clearly, such tensile residual stress was not observed experimentally (see Figs. 9a and 11). Most likely, the tensile stress has relaxed by crack initiation into the brittle, plastically deformed expanded austenite. Indeed, cracks 
FIG. 15 Calculated composition (a) and elastic stress (b) profiles for nitrided ( $T=713 \mathrm{~K} ; \mathrm{t}=16 \mathrm{~h}$ ) and consecutively de-nitrided stainless steel AISI 316. The colored lines were obtained for de-nitriding in $\mathrm{NH}_{3} / \mathrm{H}_{2}$ gas mixtures; fully nitrided in $\mathrm{NH}_{3}$ is represented by the dashed line, while de-nitrided in $\mathrm{H}_{2}$ is represented by the drawn black line. The reduction of the nitrogen content in the plastically deformed part of expanded austenite (see Fig. 12b) leads to a conversion from compressive to tensile elastic residual stress within a narrow depth interval. (c) Micrograph of the de-nitrided specimens for which other data were shown in Fig. 9 (from Ref. [26]). The horizontal arrows indicate the locations of cracks that were most likely initiated by the introduction of tensile stress in the plastically deformed region caused by de-nitriding.
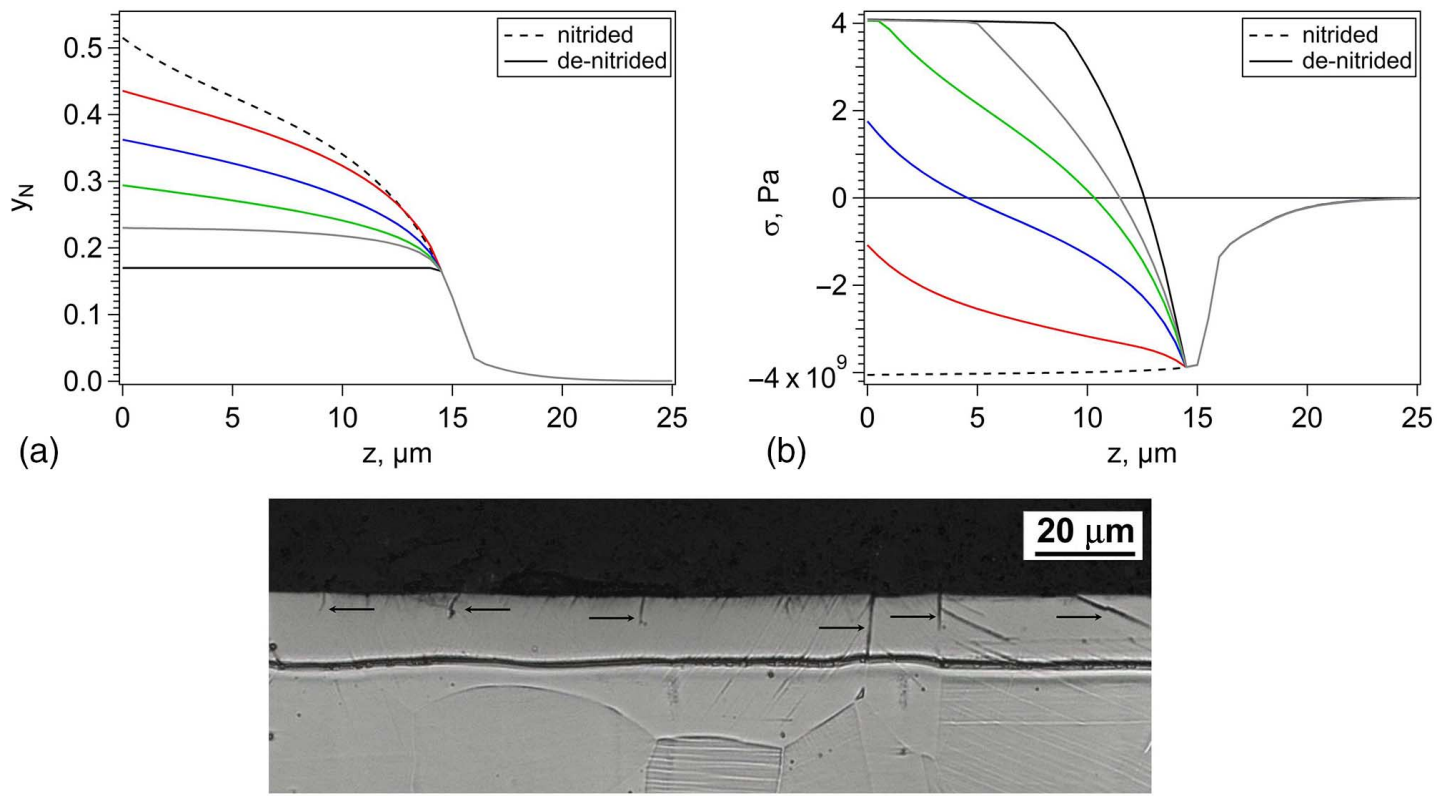

(c) 
at elevated temperatures, an additional thermal stress is superimposed on cooling as a consequence of a variation of the expansion coefficient with nitrogen content, particularly below the Curie temperature for the nitrogen content, where expanded austenite can become ferromagnetic.

For the experimental determination of elastic and plastic accommodation of the lattice expansion, X-ray diffraction lattice strain analysis was applied to unravel the contributions of composition and stress on the lattice parameter, while electron backscatter diffraction was applied to quantify the lattice rotation caused by plastic deformation. X-ray diffraction strain determination needs the adoption of appropriate measurement, correction procedures, or both to avoid artifacts caused by a variation of the information depth and the occurrence of gradients. Several procedures were described and experimentally verified, and it appears that a series of tilt angles in combination with a series of grazing incidence angles while keeping the information depth constant is a viable approach.

Numerical modeling to predict both the nitrogen concentration profile and the elastic and plastic strain profiles needs the incorporation of the coupling between diffusion and mechanical stress as well as the composition-dependent thermal expansion coefficient. The results obtained are in satisfactory agreement with the experimental observations and clearly reproduce the trends observed experimentally. An accurate prediction of the evolution of composition and stress profile is not yet possible, because austenite is strongly elastically and plastically anisotropic. Incorporation of the effects of anisotropy in the modeling will be a future challenge.

\section{ACKNOWLEDGMENTS}

The work described in this manuscript is a combination of a review of previously achieved and published results as well as the newest results of ongoing research activities. Over the years external financing was received from various sources. These donations have been acknowledged in the original references. The newest results obtained by numerical modeling were partly financed by the Innovation Fund Denmark under the strategic research center ReWind.

\section{References}

[1] Christiansen, T. L. and Somers, M. A. J., "Low Temperature Gaseous Surface Hardening of Stainless Steel: The Current Status," Int. J. Mater. Res., Vol. 100, No. 10, 2009, pp. 1361-1377, https://doi.org/10.3139/146.110202

[2] Dong, H., "S-Phase Surface Engineering of $\mathrm{Fe}-\mathrm{Cr}, \mathrm{Co}-\mathrm{Cr}$ and $\mathrm{Ni}-\mathrm{Cr}$ Alloys," Int. Mater. Rev., Vol. 55, No. 2, 2013, pp. 65-98, https://doi.org/10.1179/ 095066009X12572530170589

[3] Somers, M. A. J. and Christiansen, T. L., "Low Temperature Surface Hardening of Stainless Steel," ASM Handbook, Volume 4D: Heat Treating of Irons and Steels, J. L. Dosset and G. E. Totten, Eds., ASM International, Materials Park, OH, 2014, pp. 439-450.

[4] Somers, M. A. J. and Christiansen, T. L., "Low Temperature Surface Hardening of Stainless Steels" and "Gaseous Processes for Low Temperature Surface Hardening of Stainless Steel," Thermochemical Surface Engineering of Steels, E. J. Mittemeijer and M. A. J. Somers, Eds., Woodhead Publishing, Cambridge, United Kingdom, 2015, pp. 557-614.

[5] Fernandes, F. A. P., Christiansen, T. L., and Somers, M. A. J., "Surface Hardening: Low Temperature," Encyclopedia of Iron, Steel, and Their Alloys, R. Colas and G. A. Totten, Eds., Taylor and Francis, New York, NY, 2015, pp. 3502-3524. 
[6] Christiansen, T. and Somers, M. A. J., "Controlled Dissolution of Colossal Quantities of Nitrogen in Stainless Steel,” Metall. Mater. Trans. A, Vol. 37, No. 3, 2006, pp. 675-682, https://doi.org/10.1007/s11661-006-0039-5

[7] Christiansen, T. L., Ståhl, K., Brink, B. K., and Somers, M. A. J., "On the Carbon Solubility in Expanded Austenite and Formation of Hägg Carbide in AISI 316 Stainless," Steel Res. Int., Vol. 87, No. 11, 2016, pp. 1395-1405, https://doi.org/10. 1002/srin.201500415

[8] Christiansen, T. and Somers, M. A. J., "Avoiding Ghost Stress on Reconstruction of Stress- and Composition Depth Profiles from Destructive X-Ray Diffraction Depth Profiling," Mater. Sci. Eng., A, Vol. 424, Nos. 1-2, 2006, pp. 181-189, https://doi.org/ 10.1016/j.msea.2006.03.007

[9] Bottoli, F., Winther, G., Christiansen, T. L., Dahl, K. V., and Somers, M. A. J., "LowTemperature Nitriding of Deformed Austenitic Stainless Steels with Various Nitrogen Contents Obtained by Prior High-Temperature Solution Nitriding," Metall. Mater. Trans. A, Vol. 47, No. 8, 2016, pp. 4146-4159, https://doi.org/10.1007/ s11661-016-3559-7

[10] Oddershede, J., Christiansen, T. L., Ståhl, K., and Somers, M. A. J., “Extended X-Ray Absorption Fine Structure Investigation of Nitrogen Stabilized Expanded Austenite," Scr. Mater., Vol. 62, No. 5, 2010, pp. 290-293, https://doi.org/10.1016/j.scriptamat. 2009.11.021

[11] Cao, Y., Ernst, F., and Michal, G. M., "Colossal Carbon Supersaturation in Austenitic Stainless Steels Carburized at Low Temperature,” Acta Mater., Vol. 51, No. 14, 2003, pp. 4171-4181, https://doi.org/10.1016/S1359-6454(03)00235-0

[12] Hummelshøj, T. S., Christiansen, T. L., and Somers, M. A. J., "Lattice Expansion of Carbon-Stabilized Expanded Austenite,” Scr. Mater., Vol. 63, No. 7, 2010, pp. 761763, https://doi.org/10.1016/j.scriptamat.2010.05.031

[13] Brink, B. K, Ståhl, K., Christiansen, T. L., Frandsen, C., Hansen, M. F., and Somers, M. A. J., "Composition-Dependent Variation of Magnetic Properties and Interstitial Ordering in Homogeneous Expanded Austenite," Acta Mater., Vol. 106, 2016, pp. 32-39, https://doi.org/10.1016/j.actamat.2015.12.043

[14] Fernandes, F. A. P., Christiansen, T. L., Winther, G., and Somers, M. A. J., "On the Determination of Stress Profiles in Expanded Austenite by Grazing Incidence X-Ray Diffraction and Successive Layer Removal," Acta Mater., Vol. 94, 2015, pp. 271-280, https://doi.org/10.1016/j.actamat.2015.04.040

[15] Jespersen, F. N., Hattel, J. H., and Somers, M. A. J., "Modelling the Evolution of Composition- and Stress-Depth Profiles in Austenitic Stainless Steels during LowTemperature Nitriding," Modell. Simul. Mater. Sci. Eng., Vol. 24, No. 2, 2016, 025003, https://doi.org/10.1088/0965-0393/24/2/025003

[16] Fewell, M. P., Mitchell, D. R. G., Priest, J. M., Short, K. T., and Collins, G. A., "The Nature of Expanded Austenite," Surf. Coat. Technol., Vol. 131, Nos. 1-3, 2000, pp. 300-306, https://doi.org/10.1016/S0257-8972(00)00804-5

[17] Templier, C., Stinville, J. C., Villechaise, P., Renault, P. O., Abrasonis, G., Rivière, J. P., Martinavičius, A., and Drouet, M., "On Lattice Plane Rotation and Crystallographic Structure of the Expanded Austenite in Plasma Nitrided AISI 316L Steel," Surf. Coat. Technol., Vol. 204, Nos. 16-17, 2010, pp. 2551-2558, https://doi.org/10.1016/j. surfcoat.2010.01.041

[18] Brink, B. K., "Synthesis and Characterization of Homogeneous Interstitial Solutions of Nitrogen and Carbon in Iron-Based Lattices," Ph.D. thesis, Technical University of Denmark, Kongens Lyngby, Denmark, 2015.

[19] Genzel, C., "A Self-Consistent Method for X-Ray Diffraction Analysis of Multiaxial Residual-Stress Fields in the Near-Surface Region of Polycrystalline Materials. I. Theoretical Concept," J. Appl. Crystallogr. Vol. 32, No. 4, 1999, pp. 770-778, https://doi.org/10.1107/S0021889899005506

[20] Somers, M. A. J. and Mittemeijer, E. J., "Development and Relaxation of Stress in Surface Layers; Composition and Residual Stress Profiles in $\gamma^{\prime}-\mathrm{Fe}_{4} \mathrm{~N}_{1-\mathrm{x}}$ Layers on 


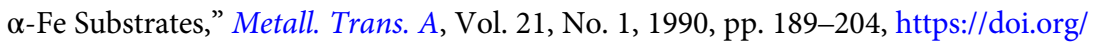
10.1007/BF02656436

[21] Moore, M. G. and Evans, W. P., "Mathematical Correction for Stress in Removed Layers in X-Ray Diffraction Residual Stress Analysis," SAE Trans., Vol. 66, 1958, pp. 340-345.

[22] Christiansen, T. L. and Somers, M. A. J., "Stress and Composition of Carbon Stabilized Expanded Austenite on Stainless Steel," Metall. Mater. Trans. A, Vol. 40, No. 8, 2009, pp. 1791-1798, https://doi.org/10.1007/s11661-008-9717-9

[23] Brink, B. K., Ståhl, K., Christiansen, T. L., Oddershede, J., Winther, G., and Somers, M. A. J., "On the Elusive Crystal Structure of Expanded Austenite," Scr. Mater., Vol. 131, 2017, pp. 59-62, https://doi.org/10.1016/j.scriptamat.2017.01.006

[24] Jegou, S., Christiansen, T. L., Klaus, M., Genzel, C., and Somers, M. A. J., "Determination of Composition, Residual Stress and Stacking Fault Depth Profiles in Expanded Austenite with Energy-Dispersive Diffraction," Thin Solid Films, Vol. 530, 2013, pp. 71-76, https://doi.org/10.1016/j.tsf.2012.06.029

[25] Tromas, C., Stinville, J. C., Templier, C., and Villechaisse, P., "Hardness and Elastic Modulus Gradients in Plasma-Nitrided 316L Polycrystalline Stainless Steel Investigated by Nanoindentation Tomography," Acta Mater., Vol. 60, No. 5, 2012, pp. 1965-1973, https://doi.org/10.1016/j.actamat.2011.12.012

[26] Fernandes, F. A. P., Christiansen, T. L., Winther, G., and Somers, M. A. J., "Measurement and Tailoring of Residual Stress in Expanded Austenite on Austenitic Stainless Steel," Mater. Sci. Eng., A, Vol. 701, 2017, pp. 167-173, https://doi.org/10.1016/j.msea.2017.06.082

[27] Christiansen, T. L., Dahl, K. V., and Somers, M. A. J., "Nitrogen Diffusion and Nitrogen Depth Profiles in Expanded Austenite: Experimental Assessment, Numerical Simulation and Role of Stress," Mater. Sci. Technol., Vol. 24, No. 2, 2013, pp. 159-167, https://doi.org/10.1179/026708307X232901

[28] Ernst, F., Avishai, A., Kahn, H., Gu, X., Michal, G. M., and Heuer, A. H., "Enhanced Carbon Diffusion in Austenitic Stainless Steel Carburized at Low Temperature," Metall. Mater. Trans. A, Vol. 40, No. 8, 2009, pp. 1768-1780, https://doi.org/10. 1007/s11661-009-9854-9

[29] Martinavičius, A., Abrasonis, G., and Möller, W., "Influence of Crystal Orientation and Ion Bombardment on the Nitrogen Diffusivity in Single-Crystalline Austenitic Stainless Steel," J. Appl. Phys., Vol. 110, No. 7, 2011, 075907, https://doi.org/10.1063/ 1.3646493

[30] Somers, M. A. J. and Christiansen, T., "Kinetics of Microstructure Evolution during Gaseous Thermochemical Surface Treatment," J. Phase Equilib. Diffus., Vol. 26, No. 5, 2005, pp. 520-528, https://doi.org/10.1007/s11669-005-0045-0

[31] Christiansen, T. L. and Somers, M. A. J., “The Influence of Stress on DiffusionCarbon Diffusion Data in Austenite Revisited," Defect Diffus. Forum, Vols. 297301, 2010, pp. 1408-1413, https://doi.org/10.4028/www.scientific.net/DDF.297-301. 1408

[32] Moskalioviene, T. and Galdikas, A., "Stress Induced and Concentration Dependent Diffusion of Nitrogen in Plasma Nitrided Austenitic Stainless Steel," Vacuum, Vol. 86, No. 10, 2012, pp. 1552-1557, https://doi.org/10.1016/j.vacuum.2012.03.026

[33] Kücükyildiz, Ö. C., Sonne, M. R., Thorborg, J., Hattel, J. H., and Somers, M. A. J., "Integrated Computational Modelling of Thermochemical Surface Engineering of Stainless Steel," presented at the 24th International Federation for Heat Treatment and Surface Engineering Congress, Nice, France, June 26-29, 2017, IFHTSE, Padova, Italy.

[34] Christiansen, T. and Somers, M. A. J., "Determination of Composition Dependent Diffusion Coefficient of Nitrogen in Expanded Austenite," Int. J. Mater. Res., Vol. 99, No. 9, 2008, pp. 999-1005, https://doi.org/10.3139/146.101729

[35] Kücükyildiz, Ö. C., Sonne, M. R., Thorborg, J., Somers, M. A. J., and Hattel, J. H. (in preparation). 
[36] Somers, M. A. J., van der Pers, N. M., Schalkoord, D., and Mittemeijer, E. J., "Dependence of Lattice Parameter of $\{\gamma$ ' $\}$ Iron Nitride, $\mathrm{Fe}_{4} \mathrm{~N}_{1-\mathrm{x}}$, on Nitrogen Content; Accuracy of the Nitrogen Absorption Data," Metall. Trans. A, Vol. 20, No. 8, 1989, pp. 1533-1539, https://doi.org/10.1007/BF02665509

[37] Ormstrup, C. A., "Influence of Stress on Diffusion of Interstitials in Stainless Steel," M. Sc. thesis, Technical University of Denmark, Kongens Lyngby, Denmark, 2016. 